\title{
Aceitação e uso da tecnologia para escolha de destinos turísticos por pessoas da terceira idade: um estudo usando a UTAUT2
}

\section{Acceptance and use of technology for the choice of touristic destina- tions by persons of the third age: a study using UTAUT2}

\section{Aceptación y uso de la tecnología para la elección de destinos turísti- cos por personas de la tercera edad: un estudio con UTAUT2}

\author{
Andréia Cássia de Moura ${ }^{1}$ \\ Marlusa de Sevilha Gosling ${ }^{2}$ \\ Juliana Maria Magalhães Christino ${ }^{3}$ \\ Sâmara Borges Macedo ${ }^{4}$
}

Resumo: Os idosos têm demonstrado crescente interesse por novas tecnologias e as relacionam com a aprendizagem, inserção social e lazer. Considerando-se o elevado número de mudanças no perfil dos idosos brasileiros e os contextos turístico e tecnológico, esse trabalho tem como objetivo compreender as intenções comportamentais e o uso da internet pela terceira idade com fins de escolhas de destinos turísticos. Para isso, o trabalho estendeu o Modelo UTAUT2 de Venkatesh, Thong e Xu (2012), inserindo novos construtos relacionados à tecnologia: Risco Percebido e Confiança, de Slade et al (2015) e também adicionando a Atitude, fundamentada por Curras-Perez, Ruiz-Mafe e Sanz-Blas (2014). O estudo caracteriza-se como exploratório-descritivo. Para tanto, realizou-se um Survey, online e presencial, sendo aplicado por dois meses. Para as análises utilizou-se técnicas estatísticas de análise multivariada, processadas pelo SPSS20 e a análise de modelagem de equações estruturais utilizando-se o SmartPLS. A amostra obtida foi de 211 idosos que usam internet para fins turísticos. Como resultado, têm-se as relações dos construtos Hábito, Motivação Hedônica, Confiança e Expectativa de Desempenho como determinantes da Atitude de uso da Internet para fins turísticos e, acrescentando-se a isso, a relação do construto Hábito afetando positivamente o Comportamento de uso. No que tange à originalidade o

${ }^{1}$ Universidade Federal de Minas Gerais (UFMG). Belo Horizonte, MG, Brasil. Elaboração do referencial teórico, coleta dos dados, tabulação, processamento e análise dos dados, redação do trabalho, preparação do artigo científico.

${ }^{2}$ Universidade Federal de Minas Gerais (UFMG). Belo Horizonte, MG, Brasil. Orientação na concepção, desenho e análise de dados do trabalho científico, revisão crítica do trabalho; aprovação final.

${ }^{3}$ Universidade Federal de Minas Gerais (UFMG). Belo Horizonte, MG, Brasil. Orientação na concepção e desenho do trabalho científico, revisão crítica do trabalho; aprovação final.

${ }^{4}$ Universidade Federal de Minas Gerais (UFMG). Belo Horizonte, MG, Brasil. Elaboração do referencial teórico, coleta dos dados, tabulação e análise dos dados, redação do trabalho, preparação do artigo científico.

Artigo recebido em: 13/01/2017. Artigo aprovado em: 29/03/2017. 
trabalho apresentou a Atitude como um conceito novo utilizado para compor o modelo, trazendo algo inédito a este campo de estudos no Brasil. Além disso, apresenta-se como uma inovação à aplicação do modelo UTAUT2 no contexto brasileiro, em um segmento e setor de mercado ainda não explorado neste campo de pesquisa - a terceira idade e o turismo.

Palavras-chave: Idoso. Destinos Turísticos. Internet. Tecnologia. Teoria Unificada de Aceitação e Uso da Tecnologia 2 (UTAUT2).*

\begin{abstract}
The elderly have shown an increasing interest in new technologies and relate them to learning, social insertion and leisure. Considering the high number of changes in the profile of the Brazilian elderly and the tourist and technological contexts, this work aims to understand the behavioral intentions and the use of the internet by the elderly for the purposes of tourist destination choices. For this, the work extended the UTAUT2 Model of Venkatesh, Thong and Xu (2012), inserting new constructs related to technology: Perceived Risk and Confidence, by Slade et al (2015) and also adding Attitude, based on Curras-Perez, Ruiz-Mafe and Sanz-Blas (2014). The study is characterized as exploratory-descriptive. For that, a Survey was conducted, online and face-to-face, being applied for two months. Statistical analysis of multivariate analysis was performed using SPSS20 and the modeling analysis of structural equations using SmartPLS. The sample obtained was of 211 elderly people who use Internet for tourist purposes. As a result, the relations of the Habit, Hedonic Motivation, Trust and Performance Expectations as determinants of the Internet Use Attitude for tourism purposes and, in addition to that, the relation of the Habit construct, positively affecting the Usage Behavior. As far as the originality of the work was concerned, Atitude was a new concept used to compose the model, bringing something unprecedented to this field of studies in Brazil. In addition, innovations include the application of the UTAUT2 model to the Brazilian context, in a segment and market sector not yet explored in this field of research - the third age and tourism.
\end{abstract}

Keywords: Elderly. Tourist Destinations. Internet. Technology. Unified Theory of Acceptance and Use of Technology 2 (UTAUT2).

Resumen: La terceira edad han mostrado un creciente interés en las nuevas tecnologías e informar al aprendizaje, la inserción social y de ocio. Teniendo en cuenta el elevado número de cambios en el perfil de las personas mayores de Brasil y los contextos turísticos y tecnológicos, este trabajo tiene como objetivo comprender las intenciones de comportamiento y el uso de Internet por parte de los ancianos a los efectos de opciones de destino turístico. Para ello, el trabajo se extendió el modelo de UTAUT2 Venkatesh, tanga y Xu (2012), la inserción de nuevas construcciones relacionadas con la tecnología: La percepción del riesgo y confianza, por Slade et al (2015) y la actitud también añadir, basado en Curras-Pérez Ruiz-Mafe y Sanz-Blas (2014). El estudio se caracteriza exploratorio-descriptivo. Para ello, la encuesta se realizó, en línea y cara a cara, que se aplica desde hace dos meses. El análisis estadístico de análisis multivariante se realizó mediante SPSS20 y el análisis de modelos de ecuaciones estructurales utilizando SmartPLS. La muestra obtenida fue de 211 personas mayores que utilizan Internet con fines turísticos. Como resultado, las relaciones del hábito, la motivación hedonista, la confianza y las expectativas de rendimiento de los determinantes de Internet Uso de la actitud para fines turísticos y, además de hacer cola, la relación de la construcción del hábito, que afectan positivamente el comportamiento de uso. En cuanto a la originalidad de la obra fue la preocupación actitud era un nuevo concepto que se utiliza para componer el modelo, trayendo algo sin precedentes para este campo de estudios en Brasil. Además, las innovaciones incluyen la aplicación del modelo UTAUT2 al contexto brasileño, en un segmento y segmento de mercado aún no explorado en este campo de la investigación - la tercera edad y el turismo.

Palabras Clave: Tercera Edad. Destinos Turísticos. Internet. Tecnología. Teoría Unificada de Aceptación y Uso de la Tecnología 2 (UTAUT2).

\section{INTRODUÇÃO}

Para a Organização Mundial da Saúde
(OMS), idoso é definido de acordo c om o nível de desenvolvimento dos países e da idade cronológica, portanto, em países desenvolvi- 
dos, são considerados idosos indivíduos com 65 anos ou mais, já em países em desenvolvimento, aqueles com 60 anos ou mais (Ibge, 2015).

Estimativas do Instituto Brasileiro de Geografia e Estatística (IBGE, 2015) apontam o envelhecimento populacional, com estimativas de que em 2020 serão 21,2 idosos para cada 100 pessoas em idade ativa, e 51,9 em 2050. Apesar do notório crescimento, estratégias próprias para esse segmento precisam ser aprimoradas (Pereira, Waismann \& Dos Santos, 2012).

Durante muito tempo os idosos foram subjugados e relacionados ao assistencialismo, ineficiência, improdutividade e à pobreza (Gomes \& Moreira, 2016). Perfil bem diferente do identificado por Vilela, Carvalho e Araújo (2006), em que constataram que os idosos têm como aspirações: satisfazer necessidades afetivas, socioeconômicas, incluindo trabalho, praticar exercícios físicos, ter espiritualidade, dentre outros. Mediante tais motivações, o turismo pode ser visto tanto como acesso a interações sociais e melhoria na qualidade de vida (Liz, Ruschmann \& Verdinelli, 2011), como também uma oportunidade de negócio crescente quando voltado à terceira idade (De Carvalho \& Da Silva, 2014). Associado a isso, os idosos têm demonstrado crescente interesse por novas tecnologias e as relacionam com a aprendizagem, inserção social e lazer, tornando-se necessário o aprimoramento de estratégias mercadológicas a esse público com relação à sua utilização de tecnologias digitais que tenham maior interface com a atividade turística (Esteves \& Slongo, 2012).

No Brasil, de acordo com a pesquisa do Comitê Gestor da Internet no Brasil (CGI, 2013), há uma contínua ampliação na proporção de usuários de Internet, bem como a intensificação da frequência de uso da internet pelos usuários brasileiros. Em 2013, a proporção de usuários de Internet ultrapassou, pela primeira vez, a metade da população, chegando a 51\%. Entre o público de 60 anos ou mais, $11 \%$ relataram ser usuários de internet e, segundo dados da nova edição da pesquisa de 2014, esse número cresceu para 18\% nesta faixa etária (CGI, 2014). Considerando as atividades de comunicação realizadas na internet, a participação dos usuários da terceira idade em redes sociais tem uma frequência de $(60 \%)$, enquanto que a atividade mais citada por este público é o uso do e-mail (77\%) e, em segundo lugar a atividade que se destaca é enviar mensagens instantâneas (70\%), por exemplo, por Facebook, Skype, WhatsApp (CGI, 2013).

Considerando-se o elevado número de mudanças no perfil dos idosos brasileiros e os contextos turístico e tecnológico, esse trabalho busca uma maior compreensão sobre as intenções comportamentais e o uso da internet pela terceira idade com fins de escolhas de destinos turísticos.

Para tal, adotou-se o Modelo UTAUT2 (Unified Theory of Acceptance and Use of Technology) desenvolvido por Venkatesh, Thong e Xu (2012), assim como foram inseridos novos construtos relacionados à tecnologia, sendo eles Risco Percebido e Confiança, constantes no trabalho de Slade et al. (2015) e também foi adicionando o construto Atitude fundamentado no trabalho de CurrasPerez, Ruiz-Mafe e Sanz-Blas (2014) e Nysveen e Pedersen (2016). A inserção deste 
último construto partiu da suposição de que a Atitude é um importante determinante do modelo, o que encontra respaldo nos trabaIhos de Ajzen (1991), Ramalho (2006), Curras-Perez, Ruiz-Mafe e Sanz-Blas (2014) e Nysveen e Pedersen (2016). Mais especificamente, objetivou-se (1) investigar as dimensões de adoção de tecnologia com base no UTAUT2 estendido ao contexto brasileiro de buscas e escolhas de destino turístico por idosos, (2) relacioná-las à atitude, intenção comportamental e ao uso da internet e (3) testar a plausibilidade deste modelo modificado proposto a fim de compreender a aceitação da tecnologia e, em um contexto diferente do original, abordando o turismo e o segmento da terceira idade,

$O$ presente trabalho justifica-se à medida que busca contribuir com o aprofundamento e solidificação do modelo teórico proposto pelos autores Venkatesh, Thong e Xu (2012), que sugerem como temas de pesquisas futuras abordar um público com idade mais avançada, uma vez que a média de idade no estudo original foi de 31 anos e, ainda recomendam aplicar o modelo em outros países e contextos, dado que o estudo desses autores ocorreu em Hong Kong. O trabalho em questão se propõe suprir estas duas lacunas por escolher como público-alvo a terceira idade brasileira, no contexto do turismo e, além disso, considerar o uso da internet de forma geral, diferente da abordagem dos autores do modelo original que se restringiu a internet móvel. Outro ponto relevante é buscar estender o modelo original com construtos pertinentes à área de tecnologia, bem como considerar a Atitude como conceito a compor o modelo, trazendo algo inédito a este campo de estudos no Brasil.

\section{REFERENCIAL TEÓRICO}

\subsection{A terceira idade, o turismo e a tecnolo- gia}

A estrutura etária do Brasil tem sofrido significativas mudanças, isso em função da queda acentuada dos níveis de fecundidade, ocasionando uma transição demográfica. A pirâmide populacional brasileira possuía a base larga, ou seja, havia uma considerável população jovem. Com o envelhecimento da população, essa proporção vem sofrendo alteração, aumentando assim a proporção de adultos e idosos (IBGE, 2015). O aumento da população idosa não é influenciado somente pela queda da taxa de fecundidade, é influenciado também pela queda da mortalidade em todas as idades (IBGE, 2015).

Kuo, Chen e Wu (2012), atribuem essa longevidade aos avanços da ciência médica. O estudo do IBGE (2015) vai ao encontro dessa afirmativa ao apresentar dados de uma pesquisa que indica que a população idosa é a que mais cresce, estimando um aumento de mais de $4 \%$ ao ano no período de 2012 a 2022. Estima-se que em 2030 a população com 60 anos ou mais será de aproximadamente 41,5 milhões, e de 73,5 milhões em 2060 (IBGE, 2015).

Santos (2010) defende o envelhecimento de maneira digna, considerando-o como uma fase de sabedoria e uma fase feliz da existência. Nesse sentido, ao turismo são atribuídos vários benefícios quando voltados à terceira idade, como independência e autonomia (Cress, Buchner, Questad, Esselman \& Schwartz, 1999 e Ashton, Cabral, Dos Santos \& Kroetz, 2015) e ganhos voltados à saúde 
(Cress et al., 1999 e Fechine \& Trompieri, 2015).

É possível observar a representatividade da parcela idosa da sociedade. Segundo Ashton et al. (2015), o turismo voltado à terceira idade é um segmento que se amplia a cada dia, proporcionando emergentes oportunidades de negócios (Mello, De Liz \& Verdinelli, 2015), tais oportunidades extensivas as agências de viagens, rede hoteleira, serviços direcionados a alimentação e de transporte (Trigo, 2005). Considerando-se que as próximas gerações de idosos tendem a ter o nível de escolaridade mais alto, consequentemente maior nível de renda, esse mercado tende a continuar promissor (Mello, De Liz \& Verdinelli, 2015).

Os idosos acreditam que o turismo contribui para a qualidade de vida e o relacionam a sentimentos positivos como alegria, bem-estar e sociabilidade (Pereira, Waismann \& Dos Santos, 2012). Kim, Woo e Uysal (2015), estudaram experiência de turismo e qualidade de vida entre os turistas idosos e constataram que quanto maior o nível de envolvimento maior será o valor percebido e o aumento da satisfação com a vida, ou seja, há a relação positiva entre a satisfação e lazer com a qualidade de vida global dos idosos. As experiências dos turistas e atividades de turismo tendem a afetar positivamente diversos domínios da vida: como a vida familiar, social, o lazer, vida cultural, entre outros (Uysal, Sirgy, Woo \& Kim, 2016). Nesse sentido, cabe aos gestores atentarem-se à qualidade das experiências turísticas dos idosos (Kim, Woo \& Uysal, 2015).

Vários são os benefícios atribuídos à pratica turística na terceira idade: autonomia, independência (Cress et al., 1999 e Ashton et al., 2015), ganhos voltados à saúde (Cress et al., 1999 e Fechine \& Trompieri, 2015), atenuante de perdas e solidão atribuídas à idosos (Ashton et al., 2015). Ashton et al. (2015) atribuem ainda, sentimento de pertencimento, utilidade, de capacidade de realização de inúmeras coisas, possibilidades de novas descobertas, melhoria da autoestima e autoconfiança. Prazer, socialização, satisfação pessoal, superação da monotonia cotidiana também foram atribuídos como benefícios (D'alencar \& Veiga, 2014).

O turismo voltado a esse público deve visar o bem-estar e o atendimento as necessidades específicas (Duarte, Santos \& Souza, 2015). As adaptações proporcionam um atendimento de maior qualidade, mais lazer aos idosos, consequentemente um aumento na demanda (Duarte, Santos \& Souza, 2015). Para D'Alencar e Veiga (2014), não bastam apenas adaptações estruturais, é necessário atentar-se às atitudes, há necessidade de treinamento para os funcionários desenvolverem melhores práticas para lidarem com esse público. Conveniência, conforto e segurança (Moura, Souza, Medeiros \& Maracajá 2012) são critérios essenciais ao considerar o público idoso (Schein, Perin, Sampaio \& Ugalde, 2009).

Como exposto, entender e atender bem esse público é uma forma de benefício mútuo, à medida que, auxiliando os idosos as empresas conquistam para si esse segmento, tido como promissor. Uma forma de atender a esse público é considerar o ciberespaço como um canal de comunicação importante 
o qual, segundo Souza (2016) está diretamente relacionado ao turismo por viabilizar e auxiliar em diversas situações, tais como sistemas de reserva hoteleira online, usar as redes sociais para o compartilhamento de informações e serviços turísticos. Vários estudos recentes têm mostrado a importância de aplicações móveis para fazer reservas em hotel, organizar excursões, e fornecer informação turística (Noguera, Barranco, Segura \& Martínez, 2012; Rodriguez-Sanchez, Martinez-Romo, Borromeo, \& Hernandez-Tamames; 2013).

Apesar de os idosos apresentarem obstáculos para a adoção de novas tecnologias, como: a) desafios físicos para usar a tecnologia: muitos idosos têm problemas de saúde ou restrições na condição física; b) muitos são céticos sobre os benefícios da tecnologia; e c) outros apresentam dificuldades de aprendizagem para usar novas tecnologias (CGI, 2014), no Brasil, os idosos vêm utilizando dispositivos móveis com mais frequência (Santos, Ishitani \& Nobre, 2013). A pesquisa do International Game Developers Association (IGDA) (2008) menciona que os idosos adotam uma inovação tecnológica quando identificam alguma utilidade para sua vida, eles não adotam algo somente pelo fato de ser novo.

Segundo um estudo do Pew Research Center-PRC (2014), os índices de adoção de Internet e de banda larga entre os idosos estão aumentando progressivamente nos Estados Unidos. Esse crescimento também ocorre em vários outros países, como a Coréia, por exemplo, onde se deu o trabalho dos autores Kim e Preis (2015). Os dados do PRC apontaram que, seis em cada dez idosos americanos, em 2014, relataram usar a internet (59\% dos respondentes), e pouco menos de metade são adotantes de banda larga.

$\mathrm{O}$ acesso às redes sociais, é um dado importante, pois como Qualman (2011), Baird e Parasnis (2011) e Moura, Godinho, Gosling e Martins (2014) apontam, os consumidores estão aumentando o uso das mídias sociais e redes sociais para ganhar recomendações, comentários e opiniões de amigos, família e comunidade social. Então considerando o construto influência social que será adiante tratado, as redes sociais podem ser um meio de propagação desta influência. As redes sociais possibilitam e facilitam também o acesso à informações turísticas (Guerra, Gosling \& Coelho, 2014).

$\mathrm{O}$ acesso à internet via dispositivos móveis tais como smartphones e tablets, tem sido muito comum recentemente, para o público em geral no Brasil e no mundo. Para o público específico da pesquisa, os idosos, o Pew Research Center (2014) aponta crescente e rápida adoção destes dispositivos móveis por essa faixa etária entre os americanos, sendo encontrado que: os idosos são mais propensos a possuir um tablet ou ebook reader do que smartphone. Apenas $18 \%$ dos idosos usam smartphones enquanto que $77 \%$ usam o telefone celular comum.

No Brasil, a realidade é um pouco diferente, o acesso à internet pelo telefone celular abrange apenas $6 \%$ dos idosos, sendo que nas outras parcelas da população o telefone celular é o dispositivo mais utilizado. Dentre os usuários brasileiros de internet com 60 anos ou mais, $78 \%$ citam o computador de mesa (desktop) como o principal dispositivo de acesso à Internet (CGC, 2014). 


\subsection{Modelo TPB, Modelo UTAUT e UTAUT2}

A Teoria do Comportamento Planejado (TPB) de Ajzen (1991) é uma extensão da Teoria do Ação Fundamentada de Fishbein e Ajzen (1975), e foi desenvolvido para explicar o comportamento individual com base nas crenças-atitudes-intenções-comportamentos (Curras-Perez, Ruiz-Mafe \& SanzBlas, 2014). Na TPB a atitude é então, antecessora de intenção comportamental. Os autores Curras-Perez, Ruiz-Mafe e Sanz-Blas (2014) também consideram a atitude como predecessora do comportamento e concebem o seu modelo relacionando os determinantes sociabilidade, moda/status e entretenimento (oriundos da Teoria de Usos e Gratificações) ao construto Atitude e utilizam, adicionalmente, as variáveis da TPB para explicar o comportamento de uso de rede social.

Tomando como base os referidos trabalhos citados anteriormente que apontam a Atitude como predecessora de Intenção Comportamental, o presente trabalho terá como pressuposição essa relação a qual será inserida no modelo UTAUT2 estendido, e os preditores do modelo UTAUT2 serão diretamente ligados à Atitude, relação explicada mais adiante.

A UTAUT (Unified Theory of Acceptance and Use of Technology) é resultado de uma revisão realizada por Venkatesh et al. (2003) de modelos anteriores que tratam da aceitação e o uso de tecnologia. Os modelos são: Theory of Reasoned Action (TRA) ; Tecnology Acceptance Model (TAM) ; Motivacional Model (MM); Theory of Planned Behavior (TPB); TPB e TAM combinados (C-TPBTAM); Model of PC Utilization (MPCU); Inova tion Diffusion Theory (IDT) e Social Cognitive Theory (SCT).

Um construto que inicialmente foi testado por Venkatesh et al. (2003), constante na teoria TPB - Theory of Planned Behavior - a atitude, não foi incorporado no UTAUT2 por não se mostrar significativo no estudo destes autores. No entanto, tal construto foi adicionado ao modelo proposto nessa pesquisa pela suposição de melhorar o modelo. $O$ recente trabalho de Nysveen e Pedersen (2016) corrobora com essa suposição, os quais adaptaram o UTAUT utilizando o construto atitude como antecedente de intenção de uso e encontrando bons resultados de ajuste do modelo proposto. A atitude é um forte preditor de intenção comportamental conforme o trabalho de vários autores e significa uma predisposição para o comportamento (Ajzen, 1991, Ramalho, 2006, Curras-Perez, Ruiz-Mafe \& Sanz-Blas, 2014, dentre outros conceituados). No contexto da tecnologia, Venkatesh (2003) define a atitude como uma reação afetiva global do indivíduo ao uso de um sistema.O presente artigo, como já mencionado, é uma extensão do artigo desenvolvido por Venkatesh, Thong e Xu (2012), e apresenta como inovações (a) a aplicação ao contexto brasileiro, (b) a inclusão de construtos, (c) a mudança no perfil dos respondentes, sendo agora a terceira idade e (d) alteração do setor estudado, o turístico. É possível notar o crescente número de estudos utilizando o modelo UTAUT, porém em contextos diferentes do estudo em questão.

Internacionalmente, é possível emcontrar temáticas diversas. Há estudos voltados à aceitação e uso da tecnologia de 
serviço de identificação por radiofrequência (Nysveen \& Pedersen, 2016), de serviços bancários em plataformas móveis na Tailândia (Bhatiasevi, 2015), sobre a intenção de uso do $Q R$ code por usuários finais, em Portugal (Luz, 2016). Rho, Kim, Chung e Choi (2015), estudaram os fatores que influenciam a aceitação do serviço de telemedicina por pacientes portadores de diabetes mellitus. Slade et al. (2015), que é um dos estudos que o presente trabalho seguiu, aplicaram a UTAUT a pagamentos móveis por celular.

No Brasil, os estudos seguem a mesma tendência internacional, ou seja, mostram-se crescentes, porém em áreas diversas, diferentes da vertente turística aqui trabalhada. Como exemplo tem-se o trabalho de Vera (2014), que estudou os fatores motivadores de compras coletivas na internet com base na UTAUT2. Lima Faria et al. (2014) estudaram a aplicabilidade da UTAT2 no Brasil a partir de usuários de internet em smartphones. Souza Meirelles e Longo (2015) pesquisaram a adoção de tecnologia de informação por parte do corpo docente de uma instituição de ensino. Outros autores nesta mesma área de pesquisa, (Oliveira, Ramos, Andrade, Souza Neto e Dias, 2015), estudaram os fatores influenciadores da adoção de capacitação a distância de funcionários públicos. Oliveira (2015) analisou como a utilização de jogos online interfere na otimização do processo seletivo em uma empresa de consultoria.

Os exemplos apresentados demonstram a variedade de estudos que utilizaram o modelo UTAUT2 e corroboram com a importância em estudá-lo em um novo contexto, ainda pouco explorado, o turístico.
No modelo UTAUT original, quatro construtos influenciam diretamente a aceitação da tecnologia e o comportamento de uso: expectativa de desempenho, expectativa de esforço, influência social e condições facilitadoras. Nesse modelo, quatro modera dores dessas relações foram utilizados: gênero, idade, experiência e voluntariedade (Farias, Luz Vitor, Lins \& Pedroza Filho, 2015). De acordo com o exposto, a UTAUT é a unificação de vários modelos concebidos para analisar o fenômeno de aceitação individual de tecnologia no contexto laboral. Posteriormente Venkatesh, Thong e Xu (2012) propuseram a UTAUT2 visando estender o modelo para fins de análise do consumo individual de tecnologia, permitindo a utilização do modelo na pesquisa do comportamento do consumidor (Lima Faria, Giuliani, Pizzinatto, \& Pizzinatto, 2014 e Farias et al., 2015). Para o UTAUT2, as variáveis - motivação hedônica, valor do preço e hábito - foram incorporadas e os moderadores das relações utilizados foram idade, gênero e experiência. Sinteticamente, o modelo preconizado por esses autores aponta os construtos expectativa de desempenho, expectativa de esforço, influência social, condições facilitadoras, motivação hedônica, valor do preço e hábito como preditores de intenção comportamental e, esta última, como determinante de comportamento de uso. O modelo também prevê os construtos condições facilitadoras e hábito influenciando diretamente o comportamento de uso.

Assim, como o objetivo do trabalho é verificar a adoção e a aceitação da internet no contexto de escolha do destino turístico, o UTAUT2 foi o modelo usado como base 
teórica da presente pesquisa. Além do UTAUT2 estendido por Slade et al. (2015), houve a adição do construto Atitude, convergindo para um modelo modificado proposto que será adiante explicitado.

Os construtos do UTAUT2 que foram adotados na pesquisa, bem como as hipóteses derivadas deste modelo original, devido à inserção do construto Atitude, aqui, enfocados no contexto do uso da internet por idosos para fins turísticos, são:

O construto "expectativa de desempenho" refere-se ao grau em que o uso de uma tecnologia fornecerá benefícios para os consumidores no desempenho de determinadas atividades (Venkatesh, Thong \& Xu, 2012). Em seu modelo original Venkatesh et al. (2003) encontraram expectativa de desempenho sendo preditora de intenção comportamental. A mesma relação é confirmada nos trabalhos de Bhatiasevi (2015), Rho, Kim, Chung e Choi (2015), Slade et al. (2015), Vera (2014) e Lima Faria et al. (2014). Como a premissa no presente trabalho é de que a Atitude precede a intenção comportamental e também com suporte nos resultados de Nysveen e Pedersen (2016) que confirmaram em seu estudo que a Expectativa de desempenho tem uma influência positiva sobre a atitude de usar serviços de identificação por radiofrequência , formulou-se a seguinte hipótese:

H1: A Expectativa de desempenho afeta positivamente a Atitude em relação ao uso da internet para o turismo.

A "expectativa de esforço" é "o grau de facilidade associado ao uso da tecnologia pelos consumidores "( Venkatesh, Thong \& $\mathrm{Xu}, 2012$, p.159). Esse construto no modelo dos referidos autores é hipotetizado como tendo um efeito significativo positivo na intenção comportamental. Trabalhos posteriores como os Bhatiasevi (2015), Rho, Kim, Chung e Choi (2015) e Lima Faria et al. (2014) confirmam tal relação. Com a inserção do construto Atitude e embasamento em Nysveen e Pedersen (2016) e outros autores já citados que tratam a atitude como antecedente de intenção comportamental, enunciase a hipótese $\mathrm{H} 2$ :

H2: Expectativa de esforço afeta positivamente a Atitude em relação ao uso da internet para o turismo.

$A$ "influência social" no contexto do consumidor refere-se ao grau em que o indivíduo acredita que os outros indivíduos consideram importante que a tecnologia seja utilizada. A pressuposição subjacente é o que os indivíduos tendem a consultar suas redes sociais sobre novas tecnologias e pode ser influenciada pela pressão social percebida de outras pessoas que consideram importantes. No modelo original de Venkatesh, Thong e Xu, (2012) a influência social é também um dos determinantes da intenção comportamental. Tal relacionamento é corroborado por estudos a posteriori (Bhatiasevi, 2015, Rho, Kim, Chung e Choi, 2015, Slade et al., 2015 e Vera, 2014). Considerando a atitude como predecessora de intenção comportamental, a hipótese 3 (H3) fica assim enunciada:

H3: A influência social afeta positivamente a Atitude em relação ao uso da internet para o turismo.

Outros construtos considerados preditores de intenção comportamental no modelo UTAUT2, são, a "motivação hedônica" 
que refere-se à diversão e/ou ao prazer proporcionado ao indivíduo pelo uso da tecnologia em questão; o "hábito" o qual tem sido definido como a medida em que as pessoas tendem a comportamentos automáticos devido à aprendizagem (Limayem, Hirt \& Cheung, 2007) e "condições facilitadoras". O modelo original prevê que o hábito tem influencia direta sobre a intenção comportamental e direta sobre o comportamento de uso. O hábito como preditor de intenção comportamental é confirmado nos estudos de Vera (2014) e Lima Faria et al. (2014). Neste último trabalho também é encontrada a relação do hábito como preditor direto de comportamento de uso. Aqui, no presente trabalho, a suposição é que esses preditores (motivação Hedônica e hábito) têm relação com a Atitude, que precede a Intenção Comportamental, e o Hábito tem relação direta com o comportamento de uso, então as hipóteses abrangendo esses dois construtos são:

H4 - Motivação Hedônica afeta positivamente a Atitude em relação ao uso da internet para o turismo.

H5a - Hábito afeta positivamente a Atitude em relação ao uso da internet para o turismo.

H5b - Hábito afeta positivamente o comportamento de uso da internet para o turismo.

As "condições facilitadoras" referemse ao grau em que o indivíduo acredita que o ambiente oferece suporte à utilização da tecnologia em questão. No modelo UTAUT original a hipótese é de que as condições facilitadoras sejam determinantes de intenção comportamental (Venkatesh, Thong \& Xu, 2012; Nysveen \& Pedersen, 2016; Lima Faria et al.
2014) e determinantes diretos de comportamento de uso (Venkatesh, Thong \& Xu, 2012) Sendo a atitude antecedente de intenção comportamental, a pressuposição no presente estudo é de que as condições facilitadoras sejam preditoras do construto Atitude, além de influenciar diretamente o comportamento de uso da internet. Assim:

H6a-Condições Facilitadoras afetam positivamente a Atitude em relação ao uso da internet para o turismo.

H6b - Condições Facilitadoras afetam positivamente o comportamento de uso da internet para o turismo.

Por fim, apresentam-se os dois últimos construtos do modelo UTAUT2: a "intenção comportamental" que se refere à intenção de consumir determinado produto ou serviço tecnológico e o "comportamento de uso" refere-se ao ato de consumir determinado produto ou serviço tecnológico. A hipótese do modelo original e adotada no modelo proposto é:

H7 - A intenção comportamental de uso afeta positivamente o comportamento de uso de internet para o turismo.

O trabalho de Bhatiasevi (2015) reforça a hipótese 7 , pois foi encontrada uma relação positiva entre Intenção comportamental e comportamento de uso, tal como os autores do modelo original.

Considerando a adoção da internet pelo público da pesquisa e sua utilização no contexto do turismo, o UTAUT2 passou por uma análise qualitativa e, após essa análise, optou-se por retirar do modelo original o construto valor do preço por não verificar adequação ao objeto pesquisado.

Um modelo particular estendendo a 
UTAUT2 com os construtos Inovatividade, Risco Percebido e Confiança, desenvolvido por Slade et al. (2015), foi aqui considerado por ser uma iniciativa que aplica a UTAUT2 a pagamentos móveis por celular, e para o contexto da pesquisa, que é a busca de informações e escolhas voltadas ao turismo pela internet, situação que pode envolver transações pela internet, corrobora para a inserção das variáveis Risco Percebido e Confiança.

$O$ risco percebido tem sido uma extensão comum da UTAUT (Williams, Rana, Dwivedi \& Lal, 2011). Esse construto ao contrário de outros construtos do modelo UTAUT, representa um dificultador no processo de adoção. Thakur e Srivastava (2014) mencionam que seus achados suportaram a hipótese de que o Risco Percebido afeta negativamente a intenção de adoção da tecnologia.

Corroborando a adoção do construto "confiança", Lu, Yang, Chau e Cao, (2011) e Zhou (2013) a definem como uma crença subjetiva de que uma parte cumprirá suas obrigações e desempenha um papel importante nas transações financeiras eletrônicas, onde os usuários são vulneráveis a riscos de incerteza e sensação de perda de controle. Para o contexto desta pesquisa, as escolhas voltadas ao turismo pela internet podem envolver transações pela internet, fato que pode envolver e requerer confiança entre as partes. Os achados do trabalho de Slade et al. (2015) revelaram que o Risco Percebido influencia negativamente a intenção de uso. Por seu turno, a Confiança influencia negati- vamente o Risco percebido e diretamente influencia positivamente a intenção de uso, mas somente para o público que conhece previamente sobre pagamentos móveis.As hipóteses elaboradas a partir do modelo UTAUT 2 estendido com Risco Percebido e Confiança (Slade et al., 2015) como preditores de Atitude são as seguintes:

H8: O Risco Percebido afeta negativamente a Atitude em relação ao uso da internet para o turismo.

H9: A confiança afeta positivamente a atitude em relação ao uso da internet para o turismo.

H10: A confiança afeta negativamente o Risco Percebido no uso da internet.

Por fim, a última hipótese do modelo proposto, tomando como base a TPB - Theory of Planned Behavior de Ajzen (1991) que preconiza a atitude como forte preditor de intenção comportamental e também o trabaIho de Nysveen e Pedersen (2016) que confirma esta relação, é a seguinte:

H11 - Atitude afeta positivamente a intenção comportamental de uso da internet para o turismo.

Assim, após essa compilação de construtos desenvolveu-se o modelo proposto, que é uma extensão da UTAUT2, com adição de "Risco Percebido" e "Confiança", inovando com o acréscimo do construto "Atitude". A partir desse modelo proposto, são derivadas as treze hipóteses do modelo UTAUT 2 modificado proposto, exposto na Figura 1: 


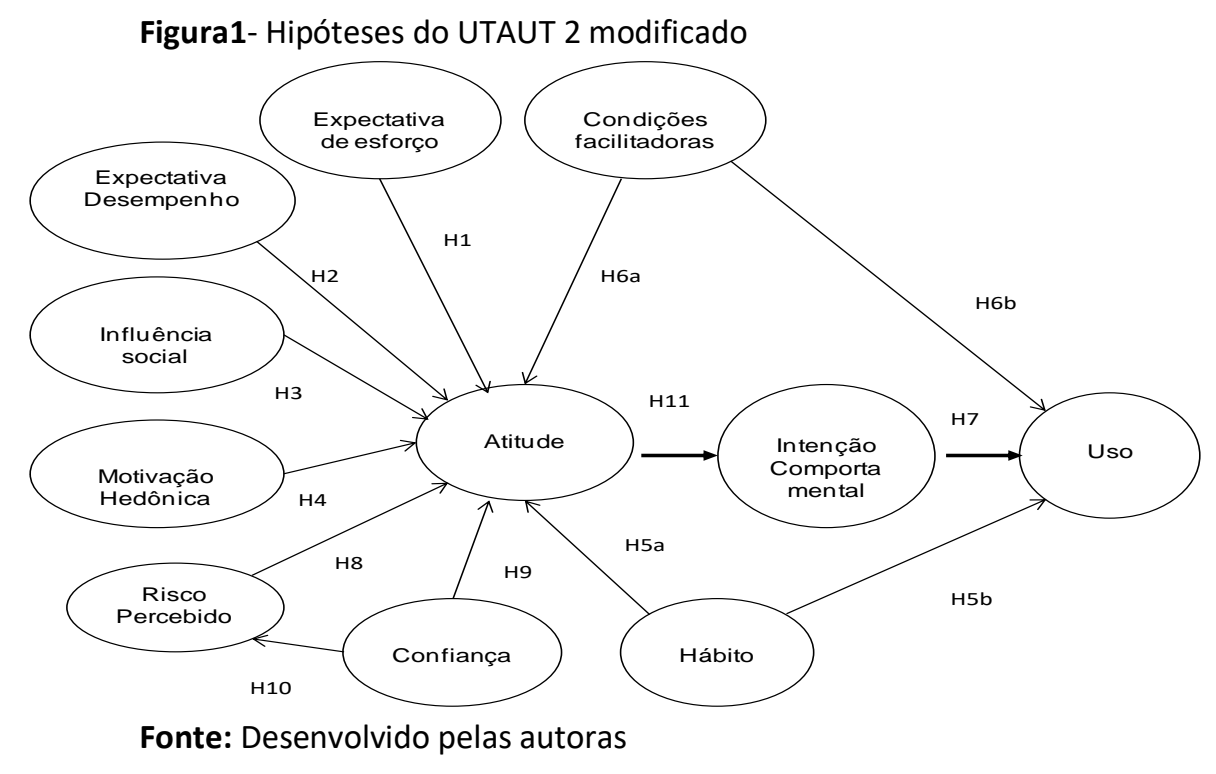

\section{PROCEDIMENTOS METODOLÓGICOS}

A presente pesquisa se inseriu na classificação de pesquisa exploratório-descritiva, uma vez que teve como objetivo examinar relacionamentos (associações) entre construtos (Malhotra, 2001). Considera-se exploratória à medida que inseriu novos construtos no modelo UTAUT2 original.

O presente artigo trata a adoção do uso da internet pela terceira idade, verificando o uso em dispositivos fixos ou móveis. Assim, averiguou-se o acesso à internet pelos idosos por meio do computador de mesa (desktop) ou dispositivos móveis (smartphones e tablets), bem como acesso a redes sociais como facebook, instagram, whatsapp, voltados ao turismo, ou seja, se há o uso desses meios para escolha de destinos turísticos. A escolha se deu pelo fato do crescente acesso de idosos à tecnologia bem como às redes sociais, conforme explicitado no referencial teórico.

A amostra foi constituída por idosos seguindo a classificação da OMS, indivíduos com 60 anos ou mais, alcançando uma amostra de 293, destes 211 válidos que são os idosos usuários de internet e para fins turísticos (que é o objeto da pesquisa). O tamanho da amostra seguiu o critério de Hair, Black, Babin, Anderson e Tatham (2010) que recomendam no mínimo 5 respondentes por parâmetro estimado. Sendo assim, como a versão final do questionário contém 38 variáveis, o número mínimo (190) de respondentes por este critério foi atingido.

Para a realização da pesquisa utilizouse o método survey, pois apresenta a vantagem de quantificação dos dados e a generalização dos dados para a população (Malhotra, 2001). O survey foi desenvolvido na plataforma Google Forms e aplicado via on-line (email e redes sociais) e também impresso e aplicado em grupos de maturidade, clubes e associação de aposentados. A coleta foi realizada nos meses de outubro e novembro de 2016 e foi aplicada a idosos da cidade de Belo Horizonte. A aplicação por meio das redes so- 
ciais foi feita em diversos grupos e comunidades da terceira idade do facebook e pelo whatsapp. A amostragem foi por conveniência, ou seja, foi enviado o link da pesquisa a idosos conhecidos das pesquisadoras. Utilizou-se também o método bola de neve, uma vez que o idoso compartilhou o link com seus conhecidos.

No presente artigo, utilizou-se uma escala Likert de 5 pontos, sendo os construtos do modelo UTAUT2 estendido proposto mensurados com âncoras 1-Discordo totalmente até 5 concordo totalmente. Para o construto comportamento de uso foram utilizadas as âncoras 1- Nunca uso até 5 Muitas vezes ao dia. Os itens da escala foram obtidos a partir dos respectivos autores relacionados no Quadro 1. No presente trabalho os moderadores referentes ao UTAUT2 original não foram utilizados, uma vez que não constituíram foco do presente trabalho.

As análises procederam por meio do software SPSS 20 e SmartPLS v. 3.2.6. As técnicas estatísticas de análise multivariada foram processadas pelo SPSS e para a análise de modelagem de equações estruturais foi utilizado o SmartPLS, uma vez que a normalidade dos dados não foi alcançada como adiante será abordado, pressuposto que não é necessário para a análise por meio deste software.

Quadro 1 - Escala utilizada na pesquisa

(continua)

\begin{tabular}{|c|c|}
\hline Itens do questionário & Autor \\
\hline \multicolumn{2}{|c|}{$\begin{array}{l}\text { Considerando o objetivo de escolher destinos turísticos, classifique seu grau de concordância com as se- } \\
\text { guintes afirmativas: }\end{array}$} \\
\hline ED1. A Internet é útil na minha vida diária para esse fim. & \multirow{13}{*}{$\begin{array}{l}\text { Venkatesh, } \\
\text { Thong e Xu } \\
(2012)\end{array}$} \\
\hline $\begin{array}{l}\text { ED2. Usar a Internet aumenta as minhas chances de alcançar coisas que são } \\
\text { importantes para mim para esse fim. }\end{array}$ & \\
\hline $\begin{array}{l}\text { ED3. Usar a Internet me ajuda a realizar as coisas voltadas a esse fim mais } \\
\text { rapidamente. }\end{array}$ & \\
\hline ED4. Usar a Internet torna minha busca voltada a esse fim mais eficiente. & \\
\hline EE1. Eu aprendo com facilidade como usar a Internet para esse fim. & \\
\hline EE2. Interagir com a Internet para esse fim é claro e compreensível. & \\
\hline EE3. A Internet é fácil de ser usada para esse fim. & \\
\hline $\begin{array}{l}\text { ED4.. É fácil para mim tornar-me mais habilidoso (a) em usar a internet para } \\
\text { esse fim. }\end{array}$ & \\
\hline $\begin{array}{l}\text { IS1. As pessoas que são importantes para mim acham que eu deveria usar a } \\
\text { Internet para esse fim. }\end{array}$ & \\
\hline $\begin{array}{l}\text { IS2. As pessoas que tem muito convívio comigo acham que eu deveria usar a } \\
\text { Internet para esse fim. }\end{array}$ & \\
\hline $\begin{array}{l}\text { IS3. As pessoas cujas opiniões eu valorizo preferem que eu use a Internet para } \\
\text { esse fim. }\end{array}$ & \\
\hline $\begin{array}{l}\text { FC1. Eu tenho os recursos necessários para usar a Internet para essa finali- } \\
\text { dade. }\end{array}$ & \\
\hline FC2. Eu tenho o conhecimento necessário para usar a Internet para esse fim. & \\
\hline
\end{tabular}


Quadro 1 - Escala utilizada na pesquisa

(conclusão)

\begin{tabular}{|c|c|}
\hline Itens do questionário & Autor \\
\hline FC3. A Internet é compatível com outras tecnologias que eu uso para esse & \\
\hline \multicolumn{2}{|l|}{$\begin{array}{l}\text { FC4. Eu posso obter ajuda de outros quando tenho dificuldades em usar a } \\
\text { internet para esse fim. }\end{array}$} \\
\hline \multicolumn{2}{|l|}{ HM1. Usar a Internet para esse fim é divertido. } \\
\hline \multicolumn{2}{|l|}{ HM2. Usar a Internet para esse fim é agradável. } \\
\hline \multicolumn{2}{|l|}{ HM3. Usar a Internet para esse fim propicia entretenimento. } \\
\hline \multicolumn{2}{|l|}{ HT1. O uso de Internet para esse fim tornou-se um hábito para mim. } \\
\hline \multicolumn{2}{|l|}{ HT2. Eu sou viciado em usar a Internet para esse fim. } \\
\hline \multicolumn{2}{|l|}{ HT3. Eu tenho que usar a Internet para esse fim. } \\
\hline \multicolumn{2}{|l|}{ HT4. Usar a Internet para esse fim tornou-se natural para mim. } \\
\hline $\begin{array}{l}\text { CF1.Eu acredito que as informações obtidas na Internet para esse fim são } \\
\text { confiáveis. }\end{array}$ & \multirow[t]{4}{*}{$\begin{array}{l}\text { Slade et al. } \\
(2015)\end{array}$} \\
\hline CF2.Eu acredito que a Internet seja segura para esse fim. & \\
\hline $\begin{array}{l}\text { CF3. Eu acredito que as informações da Internet são fidedignas para essa fi- } \\
\text { nalidade. }\end{array}$ & \\
\hline $\begin{array}{l}\text { CF4. Eu confio nas informações e nas transações realizadas por meio da In- } \\
\text { ternet para esse fim. }\end{array}$ & \\
\hline $\begin{array}{l}\text { RP1. Eu me sinto inseguro fornecendo informações pessoais na Internet para } \\
\text { esse fim. }\end{array}$ & \multirow[t]{3}{*}{$\begin{array}{l}\text { Slade et al. } \\
(2015)\end{array}$} \\
\hline $\begin{array}{l}\text { RP2. Eu me preocupo em usar a Internet para esse fim porque outras pessoas } \\
\text { podem ser capazes de acessar a minha conta. }\end{array}$ & \\
\hline $\begin{array}{l}\text { RP3. Eu me sinto inseguro enviando informações delicadas por meio da In- } \\
\text { ternet. }\end{array}$ & \\
\hline AT1. É divertido acessar a internet para fins turísticos. & \multirow{5}{*}{$\begin{array}{l}\text { Curras-Perez, } \\
\text { Ruiz-Mafe } \\
\text { Sanz-Blas, } \\
(2014)\end{array}$} \\
\hline AT2. Eu acho uma boa ideia usar a internet para esse fim. & \\
\hline AT3. É prazeroso conectar a internet para esse fim. & \\
\hline AT4. Eu acho positiva a idéia de usar a internet para fins turísticos. & \\
\hline AT5. Eu gosto de usar a internet para fins turísticos. & \\
\hline IC1. Eu pretendo continuar a usar a Internet para esse fim no futuro. & \multirow{7}{*}{$\begin{array}{l}\text { Venkatesh, } \\
\text { Thong e Xu } \\
(2012)\end{array}$} \\
\hline IC2. Eu vou sempre tentar usar a Internet para esse fim, diariamente. & \\
\hline IC3. Eu planejo continuar usando a Internet para esse fim com frequência. & \\
\hline CU1 A). Sites de busca (exemplo Google)voltado ao turismo & \\
\hline $\begin{array}{l}\text { CU2 B) Sites de busca específicos (exemplo hotel urbano, decolar. com, bo- } \\
\text { oking) }\end{array}$ & \\
\hline CU3 C) Whatsapp voltado ao turismo & \\
\hline CU4 D) Rede Sociais (exemplo Instagram, Facebook) voltado ao turismo & \\
\hline
\end{tabular}

Fonte: Adaptado de Venkatesh, Thong e Xu (2012), Curras-Perez, Ruiz-Mafe e Sanz-Blas, (2014), Slade et al. (2015)

\section{RESULTADOS E DISCUSSÕES}

\subsection{Características dos entrevistados}

Com o objetivo de conhecer e caracterizar os respondentes, na Tabela 1 são apresentadas as características específicas dessa amostra. 
Tabela 1 - Caracterização da amostra válida -Desenvolvido pelas autoras

\begin{tabular}{|c|c|c|c|}
\hline Características & Tipo & Quantidades & Percentuais \\
\hline \multirow[t]{3}{*}{ Faixa etária } & Entre 60 e 70 anos & 166 & 78,7 \\
\hline & Entre 71 e 80 anos & 38 & 18,0 \\
\hline & Mais de 81 anos & 7 & 3,3 \\
\hline \multirow[t]{3}{*}{ Sexo } & Feminino & 147 & 69,7 \\
\hline & Masculino & 61 & 28,9 \\
\hline & Dados ausentes & 3 & 1,4 \\
\hline \multirow[t]{8}{*}{ Escolaridade } & Primeiro grau incompleto & 3 & 1,4 \\
\hline & Primeiro grau completo & 2 & ,9 \\
\hline & Segundo grau incompleto & 5 & 2,4 \\
\hline & Segundo grau completo & 38 & 18,0 \\
\hline & Superior incompleto & 18 & 8,5 \\
\hline & Superior completo & 91 & 43,1 \\
\hline & Pós Graduação & 52 & 24,6 \\
\hline & Dados ausentes & 2 & 0,9 \\
\hline \multirow[t]{6}{*}{ Renda Fam. Bruta } & Até $\mathrm{R} \$ 1620,00$ & 10 & 4,7 \\
\hline & De $\mathrm{R} \$ 1620,01$ a $\mathrm{R} \$ 3240,00$ & 20 & 9,5 \\
\hline & De $\mathrm{R} \$ 3240,01$ a $\mathrm{R} \$ 5760,00$ & 52 & 24,6 \\
\hline & De $\mathrm{R} \$ 5760,01$ a $\mathrm{R} \$ 8280,00$ & 51 & 24,2 \\
\hline & Mais de $\mathrm{R} \$ 8280,01$ & 73 & 34,6 \\
\hline & Dados ausentes & 5 & 2,4 \\
\hline \multirow[t]{7}{*}{ Estado Civil } & Solteiro (a) & 18 & 8,5 \\
\hline & Casado (a) & 109 & 51,7 \\
\hline & Divorciado (a) & 33 & 15,6 \\
\hline & Viúvo (a) & 43 & 20,4 \\
\hline & Outro & 5 & 2,4 \\
\hline & Dados ausentes & 3 & 1,4 \\
\hline & TOTAL & 211 & \\
\hline
\end{tabular}

Fonte: Dados da pesquisa

Obteve-se uma amostra de 293 respondentes no período de outubro a novembro de 2016 . Destes respondentes, $6,8 \%$ possuem menos de 60 anos, sendo desconsiderados para a pesquisa; $82,9 \%$ usam a internet e 72 \% são usuários de internet para fins turísticos, num total de 211 casos considerados válidos para o estudo.

Observou-se que a amostra de idosos usuários da internet para fins turísticos é composta em sua maioria por idosos com idade entre 60 e 70 anos, representando um total de $78,7 \%$ da amostra. Indivíduos do sexo feminino apresentaram-se em maior quantidade, representado $69,7 \%$ dos usuários.

Em relação à renda, três faixas apresentaram mais representatividade, sendo de $34,6 \%$ da amostra aqueles que ganham mais de $R \$ 8280,01$, seguido por aqueles que ganham entre $R \$ 3240,01$ a $R \$ 5760,00(24,6 \%)$ e $R \$ 5760,01$ a $R \$ 8280,00$ (24,2\%). A maior parte dos respondentes declarou-se casado $(51,7 \%)$ e ensino superior completo $(43,1 \%)$.

A representatividade daqueles que ganham acima de $\mathrm{R} \$ \mathbf{8 2 8 0 , 0 0}$ e o nível de escolaridade predominante na pesquisa, vai ao encontro da tendência apresentada por 
Mello, de Liz e Verdinelli (2015), que apontaram a tendência dos idosos apresentarem nível de escolaridade mais alto influenciando o aumento no nível da renda.

\subsection{Análise outliers e dados ausentes e pres- suposto de normalidade}

Considerando os dados coletados por meio dos questionários, todas as variáveis de escala tipo likert do modelo UTAUT2 e dos construtos adicionados, apresentaram distribuição não normal, característica observada no teste de normalidade Kolmogorov-Smirnov e Shapiro-Wilk, pois a hipótese nula de normalidade em ambos os testes foi rejeitada ao nível de significância de $5 \%$.

Sobre a presença de outliers, foram encontrados 3 outliers multivariados. Esses outliers multivariados foram identificados pela medida $D^{2}$ de Mahalanobis (Hair et al., 2010). Considerando o valor crítico de 2,5 apontado por Hair et al. (2010) para amostras de 200 casos, todas as observações que tiveram esse valor ou mais nesse cálculo, foram então classificadas como outliers multivariados e foram excluídas da análise para não comprometer os resultados.

A análise de dados ausentes é pertinente uma vez que a técnica de equações estruturais é sensível a missing values. Assim, a questão concernente a dados ausentes foi tratada pelo procedimento de listwise (exclusão de casos), ou seja, só foram considerados os questionários válidos e completos para análise.
As correlações de Spearman, quando avaliadas no geral, ou seja, considerando todos os construtos, variaram de $-0,055$ a 0,836 . Todos os construtos apresentaram correlações lineares significativas, exceto comportamento de uso (algumas variáveis) e risco percebido ao nível significância de 0,01.

\subsection{Análise da dimensionalidade dos Cons- trutos}

Antes de avaliar a confiabilidade da escala pelo coeficiente alpha de Cronbach, faz-se necessária, de acordo com Hair et al., (2010), a verificação da unidimensionalidade de todos os construtos. Esta é alcançada utilizando-se o critério sugerido Sharma e Patterson (2000) que considera unidimensional todo construto que apresentar um único fator com o autovalor maior que 1 quando submetido à análise fatorial exploratória.

Para o estudo em questão, foi observado que os construtos mostraram-se unidimensionais de acordo com os resultados da Análise fatorial Exploratória (AFE) aplicada a cada construto separadamente.

Para verificar as dimensões, isto é, se os indicadores se alocam em seu respectivo construto teórico, também foi empregada a AFE, a qual permite a exploração dos dados e gera informações do número de fatores que melhor representam os dados em suas cargas fatoriais (Hair et al., 2010). A AFE também foi empregada pelo fato do presente estudo ser exploratório no que diz respeito aos construtos novos inseridos no modelo UTAUT2 original. 
Para realização desta análise, é recomendável a utilização da AFE através do método de componentes principais, com rotação ortogonal Varimax para cada construto avaliado, o qual permite alcançar o número mínimo de fatores necessários para explicar a parte máxima da variância representada no conjunto original de variáveis (Malhotra, Birks, Wills, 2012 e HAIR et al., 2010).

A partir dessa escolha de método de extração e de rotação precedeu-se a análise fatorial para os construtos determinantes (exógenos) e após, análise da dimen- sionalidade com relação aos construtos dependentes Atitude, Intenção Comportamental e Comportamento de Uso, bem como a análise das comunalidades.

Como pode ser visualizado na Tabela 2, foram identificadas 7 dimensões considerando os construtos exógenos. Como pode ser observado as variáveis dos construtos EE Expectativa de Esforço e CF Condições facilitadoras se agruparam em um mesmo fator e não em grupos distintos, ou seja, a estrutura revelou que indicadores formam um mesmo construto e não construtos distintos.

Tabela 2- Matriz rotacionada dos construtos determinantes (exógenos)

\begin{tabular}{|c|c|c|c|c|c|c|c|c|}
\hline & \multicolumn{8}{|c|}{ Componentes } \\
\hline & 1 & 2 & 3 & 4 & 5 & 6 & 7 & Comunal. \\
\hline ED1 & & & 0,638 & 0,330 & & & & 0,653 \\
\hline ED2 & & & 0,815 & & & & & 0,838 \\
\hline ED3 & & & 0,803 & & & & & 0,813 \\
\hline ED4 & 0,307 & & 0,733 & & & & & 0,705 \\
\hline EE1 & 0,812 & & & & & & & 0,767 \\
\hline EE2 & 0,728 & & & & & & & 0,711 \\
\hline EE3 & 0,792 & & & & & & & 0,758 \\
\hline EE4 & 0,734 & & & & 0,311 & & & 0,741 \\
\hline IS1 & & & & & 0,849 & & & 0,851 \\
\hline IS2 & & & & & 0,883 & & & 0,886 \\
\hline IS3 & & & & & 0,723 & & & 0,671 \\
\hline $\mathrm{MH} 1$ & & & & & & 0,799 & & 0,820 \\
\hline $\mathrm{MH} 2$ & & & & & & 0,834 & & 0,850 \\
\hline $\mathrm{MH} 3$ & & & & & & 0,850 & & 0,823 \\
\hline HT1 & 0,306 & & & 0,689 & & & & 0,777 \\
\hline HT2 & & & & 0,781 & & & & 0,739 \\
\hline HT3 & & & & 0,789 & & & & 0,790 \\
\hline HT4 & 0,347 & & & 0,612 & & 0,337 & & 0,730 \\
\hline CO1 & & 0,797 & & & & & & 0,761 \\
\hline $\mathrm{CO} 2$ & & 0,874 & & & & & & 0,858 \\
\hline $\mathrm{CO} 3$ & & 0,882 & & & & & & 0,842 \\
\hline $\mathrm{CO} 4$ & & 0,865 & & & & & & 0,818 \\
\hline RP1 & & & & & & & 0,752 & 0,644 \\
\hline RP2 & & & & & & & 0,869 & 0,766 \\
\hline RP3 & & & & & & & 0,903 & 0,821 \\
\hline CF1 & 0,448 & & 0,413 & & & & & 0,473 \\
\hline CF2 & 0,745 & & & 0,324 & & & & 0,731 \\
\hline CF3 & 0,440 & & 0,347 & 0,311 & & & & 0,473 \\
\hline CF4 & 0,380 & & & & & & & 0,297 \\
\hline
\end{tabular}

Nota: $\mathrm{KMO}=0,891$

Fonte: Dados da Pesquisa 
Além disso, as comunalidades dos indicadores CF1, CF3 e CF4 $(0,473 ; 0,473$ e 0,297 ) ficaram abaixo de 0,50 que é o mínimo recomendado por Hair et al., (2010). Portanto, optou-se em eliminar este construto, pois além das comunalidades terem sido baixas, com a eliminação do construto $\mathrm{CF}$, a variância explicada acumulada passou de $73,812 \%$ para $78,930 \%$, ou seja, um aumento considerável.

A partir da Tabela 3 é possível verificar que os indicadores dos construtos AT Atitude e IC Intenção Comportamental se agruparam em um mesmo componente, revelando que os indicadores formam um mesmo construto e não construtos distintos. A comunalidade do indicador IC2 foi abaixo do aceitável, sendo recomendável a sua retirada. Para a decisão de retirada do construto, a variância acumulada foi apurada e com a eliminação do construto IC a variância explicada acumulada aumentou de 64,829 \% para $70,963 \%$, acrescenta-se a isso o fato de não ser recomendável um construto ter somente 2 indicadores. Assim, optou-se pela retirada do construto IC da análise.
Tabela 3- Matriz rotacionada dos demais construtos

\begin{tabular}{l|l|l|l}
\hline \multirow{2}{*}{} & \multicolumn{2}{|l|}{ Componente } & \\
\cline { 2 - 4 } & 1 & 2 & $\begin{array}{l}\text { Comu- } \\
\text { nal. }\end{array}$ \\
\hline AT1 & 0,841 & & 0,716 \\
AT2 & 0,890 & & 0,806 \\
AT3 & 0,838 & & 0,715 \\
AT4 & 0,864 & & 0,756 \\
AT5 & 0,859 & & 0,807 \\
\hline IC1 & 0,756 & & 0,624 \\
IC2 & 0,531 & 0,428 & 0,465 \\
IC3 & 0,566 & 0,448 & 0,520 \\
\hline CU1_A & & 0,677 & 0,522 \\
CU2_B & & 0,731 & 0,624 \\
CU3_C & & 0,781 & 0,613 \\
CU4_D & & 0,782 & 0,612 \\
\hline
\end{tabular}

Nota: $\mathrm{KMO}=0,893$

Fonte: Dados da Pesquisa

A Figura 2 apresenta o modelo de mensuração final do modelo proposto que teve alterações em virtude dos resultados da análise fatorial exploratória, e sob o qual foram feitas todas as análises. Na figura é mostrado o modelo após o procedimento de bootstrapping que deve ocorrer para melhoria do modelo, bem como apresenta a significância das relações. 


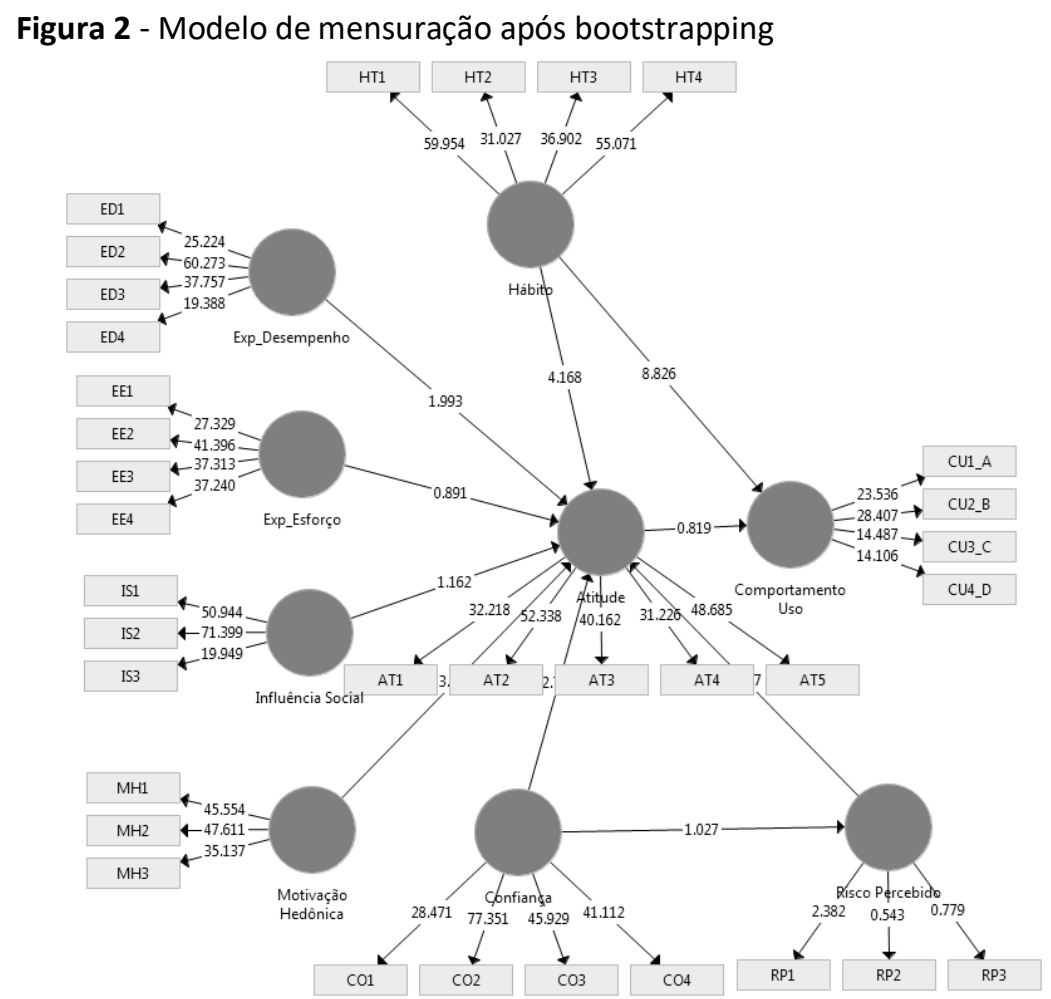

Fonte: Dados da pesquisa

\subsection{Análise da validade e confiabilidade da escala}

Para verificar a validade e confiabilidade dos construtos devem ser examinados: a consistência interna do modelo, a validade dos indicadores formadores dos construtos e a validade discriminante.

A consistência interna do modelo pode ser aferida por dois testes Alpha de Cronbach e Composite Reliability, o que pode ser visualizado na Tabela 3. Essas medidas variam de variam de 0 a 1 , de modo que, quanto maior o valor, maior será a confiabilidade.

Segundo Hair, Hult, Ringle e Sarstedt (2016), valores acima de 0,70 demonstram que os construtos são aceitáveis, sugerindo atenção para valores definitivamente acima de 0,95 para a confiabilidade composta, os quais não são desejáveis porque indicam que todas as variáveis indicadoras estão medindo o mesmo fenômeno e, portanto, são prováveis de não serem uma medida válida do construto. Como pode ser visualizado na Tabela 3, todos os valores de alpha de Cronbach e Confiabilidade Composta (Composite Reliability - $\mathrm{CR}$ ) atenderam ao recomendável pelos autores demonstrando a confiabilidade da escala do modelo em estudo.

\subsection{Validade convergente}

Avaliar a validade convergente de construtos reflexivos, os pesquisadores consideram os outer loadings dos indicadores e a variância média extraída (Average Variance Extracted - AVE). Ao analisar os Outer Loadings o recomendado por Hair et al. (2016) é que eles devem ser 0,708 ou mais e a AVE ao menos igual a 0,50 . 
Todos os valores de outer loadings e AVEs para todos os indicadores em relação aos seus respectivos construtos se mostraram aceitáveis, exceto os outer loadings dos indicadores de Risco Percebido, RP1, RP2 e RP3 se mostraram baixas $0,686,0,643$, 0,667, conforme Tabela 4.

Quando abaixo do recomendável, mas entre 0,4 e 0,7, Hair et al. (2016) sugerem que indicadores com carga externa entre esses valores devam ser considerados para remoção da escala somente quando a exclusão do indicador leva a um aumento na confiabilidade composta ou da variância média extraída. No caso em questão, não há como fazer este teste, pois remover todos os indicadores de risco, implica na remoção do construto. Então a exclusão do construto Risco Percebido não foi considerada.

Tabela 4 - Outer Loadings e AVE

\begin{tabular}{|c|c|c|c|c|c|}
\hline Construtos & Indicadores & Outer Loadings & AVE & Alfa de Cronbach & CR \\
\hline & AT1 & 0,881 & & & \\
\hline & AT2 & 0,909 & & & \\
\hline \multirow[t]{4}{*}{ Atitude } & AT3 & 0,877 & 0,789 & 0,933 & 0,949 \\
\hline & AT4 & 0,868 & & & \\
\hline & AT5 & 0,903 & & & \\
\hline & $\mathrm{CO1}$ & 0,877 & & & \\
\hline \multirow{4}{*}{ Confiança } & $\mathrm{CO} 2$ & 0,936 & 0814 & 0 Q & 0946 \\
\hline & $\mathrm{CO3}$ & 0,905 & 0,814 & $0,9<4$ & 0,940 \\
\hline & $\mathrm{CO} 4$ & 0,889 & & & \\
\hline & CU1_A & 0,797 & & & \\
\hline \multirow{4}{*}{ Comportamento Uso } & CU2_B & 0,827 & 0592 & 0775 & 0852 \\
\hline & CU3_C & 0,719 & 0,592 & $0,1 / 3$ & \\
\hline & CU4_D & 0,724 & & & \\
\hline & ED1 & 0,833 & & & \\
\hline \multirow{4}{*}{$\begin{array}{l}\text { Expectativa de Desempe- } \\
\text { nho }\end{array}$} & ED2 & 0,911 & 0725 & 0880 & 017 \\
\hline & ED3 & 0,877 & 0,135 & 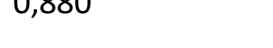 & $0,91 /$ \\
\hline & ED4 & 0,802 & & & \\
\hline & EE1 & 0,845 & & & \\
\hline \multirow{4}{*}{ Expectativa Esforço } & EE2 & 0,885 & 0758 & 0894 & 0 \\
\hline & EE3 & 0,888 & 0,/58 & 0,894 & $0,9<6$ \\
\hline & EE4 & 0,863 & & & \\
\hline & HT1 & 0,885 & & & \\
\hline \multirow{4}{*}{ Hábito } & HT2 & 0,824 & 0743 & 0885 & 0920 \\
\hline & HT3 & 0,870 & & נ, נ, & $0,9<0$ \\
\hline & HT4 & 0,867 & & & \\
\hline & IS1 & 0,920 & & & \\
\hline \multirow[t]{3}{*}{ Influência Social } & IS2 & 0,941 & 0,809 & 0,881 & 0,927 \\
\hline & IS3 & 0,832 & & & \\
\hline & MH1 & 0,913 & & & \\
\hline \multirow[t]{3}{*}{ Motivação Hedônica } & $\mathrm{MH2}$ & 0,922 & 0,825 & 0,894 & 0,933 \\
\hline & MH3 & 0,888 & & & \\
\hline & RP1 & 0,686 & & & \\
\hline \multirow[t]{2}{*}{ Risco Percebido } & RP2 & 0,643 & 0,553 & 0,818 & 0,701 \\
\hline & RP3 & 0,667 & & & \\
\hline
\end{tabular}

Nota: Após bootstrapping

Fonte: Dados da pesquisa 


\subsection{Validade discriminante}

Para se verificar a validade discriminante, utilizou-se como procedimentos de teste o critério Fornell-Larker, como pode ser visto na Tabela 5, na qual as variáveis estão codifi- cadas como a seguir: MH Motivações Hedônicas, RP Risco Percebido, CO Confiança, AT Atitude, EE Expectativa de Desempenho, EE Expectativa de Esforço, HT para Hábito, IS Influência Social e CU Comportamento de Uso.

Tabela 5- Teste de validade discriminante Fornell-Larcker Criterion

\begin{tabular}{llllllllll}
\hline \multicolumn{1}{l}{ AT } & CO & CU & ED & EE & HT & IS & MH & RP \\
\hline AT & 0,888 & & & & & & & & \\
CO & 0,467 & 0,902 & & & & & & & \\
CU & 0,395 & 0,295 & 0,770 & & & & & & \\
ED & 0,508 & 0,395 & 0,420 & 0,857 & & & & \\
EE & 0,489 & 0,379 & 0,436 & 0,576 & 0,871 & & & \\
HT & 0,628 & 0,486 & 0,579 & 0,574 & 0,555 & 0,862 & & & \\
IS & 0,331 & 0,319 & 0,407 & 0,508 & 0,376 & 0,487 & 0,900 & & \\
MH & 0,566 & 0,301 & 0,371 & 0,464 & 0,474 & 0,543 & 0,393 & 0,908 & \\
RP & 0,047 & 0,187 & 0,036 & 0,121 & $-0,073$ & 0,056 & 0,174 & 0,073 & 0,560 \\
\hline
\end{tabular}

Fonte: Dados da pesquisa

A validade discriminante é a extensão em que um construto é verdadeiramente distinto de outros construtos (Hair et al., 2016). Segundo os autores pelo critério de FornellLarker é obtida a raiz quadrada da AVE de cada construto constante da diagonal principal. Esta deve ser maior do que a correlação entre o construto e outros construtos do modelo, contida nas outras células. Como pode ser visualizado na Tabela 5, a validade discriminante pelo Fornell-Larker criterion pode ser considerada satisfatória.

\subsection{Análise dos resultados do modelo estru- tural}

Todos os indicadores dos construtos demonstraram possuir relevância para o mo- delo estrutural ( $p$ values significativos ao nível de 0,05$)$, exceto os indicadores do construto Risco Percebido, considerando os outer weights e os outer loadings (RP2 e RP3).

Para avaliar a significância das relações entre os construtos, foram analisados somente os efeitos diretos dos construtos; portanto, a técnica utilizada foi Path Coefficients constante no SmartPLS, a qual apresenta os relacionamentos entre os construtos e sua significância, sendo também possível verificar as hipóteses do modelo (Tabela 6). A significância das relações somente é obtida após rodar a função Bootstrapping para a estimativa das relações do modelo estrutural, por esse procedimento também é possível melhorar o ajuste do modelo (Hair et al., 2016). 
Tabela 6- Path Coefficients após bootstrapping

\begin{tabular}{llllll}
\hline & $\begin{array}{l}\text { Amostra } \\
\text { Original }\end{array}$ & $\begin{array}{l}\text { Média } \\
\text { Amostra }\end{array}$ & SD & Estatística & \multirow{2}{*}{ P valor } \\
\hline AT $>$ C CU & 0,052 & 0,056 & 0,066 & 0,799 & 0,424 \\
CO -> AT & 0,182 & 0,180 & 0,067 & 2,723 & 0,006 \\
CO -> RP & 0,187 & 0,056 & 0,180 & 1,035 & 0,301 \\
ED -> AT & 0,128 & 0,125 & 0,063 & 2,026 & 0,043 \\
EE -> AT & 0,065 & 0,070 & 0,072 & 0,905 & 0,366 \\
HT -> AT & 0,316 & 0,311 & 0,076 & 4,176 & 0,000 \\
HT -> CU & 0,546 & 0,548 & 0,063 & 8,678 & 0,000 \\
IS -> AT & $-0,077$ & $-0,074$ & 0,066 & 1,160 & 0,246 \\
MH -> AT & 0,282 & 0,286 & 0,073 & 3,870 & 0,000 \\
RP $\rightarrow$ AT & $-0,022$ & $-0,005$ & 0,056 & 0,393 & 0,695 \\
\hline
\end{tabular}

Fonte: Dados da pesquisa

Pela análise apresentada, cinco relações entre construtos não se mostraram significantes, quais sejam, Atitude e Comportamento de Uso, Confiança e Risco Percebido, Expectativa de Esforço e Atitude, Influência Social e Atitude e, por fim, Risco Percebido e Atitude.

As relações que se confirmaram como significantes no modelo estrutural foram cinco: Confiança e Atitude, Expectativa de Desempenho e Atitude, Hábito e Atitude, Há- bito e Comportamento de uso, Motivação Hedônica e Atitude.

Após esta verificação das relações, apurou-se a acurácia preditiva do modelo, o que pode ser atestado $R^{2}$ value (Hair et al., 2010). Tal medida mensura a acurácia preditiva do modelo, representando os efeitos combinados das variáveis endógenas sobre as variáveis exógenas, como pode ser visualizado na Tabela 7.

Tabela 7 - $\mathrm{R}^{2}$ do modelo após bootstrapping

\begin{tabular}{llllll}
\hline & Amostra & Média & & & \\
& Original & Amostras & DP & Estatística T & P Valor \\
\hline AT & 0,513 & 0,535 & 0,056 & 9,239 & 0,000 \\
CU & 0,337 & 0,346 & 0,049 & 6,851 & 0,000 \\
RP & 0,035 & 0,036 & 0,025 & 1,407 & 0,160 \\
\hline
\end{tabular}

Fonte: Dados da pesquisa

O valor de $R^{2}$ varia de 0 a 1 , de modo que, quanto mais próximo de 1 , maior será a acurácia preditiva; nos estudos sobre marketing, valores próximos a $0,25,0,50$ ou 0,75 são considerados, respectivamente, como de grau: fraco, moderado e substancial (Hair et al., 2010). No estudo em questão os $R^{2}$ values demonstraram que o modelo possui moderada acurácia preditiva em relação ao cons- truto Atitude $(0,535)$ e pouca acurácia preditiva em relação ao construto Comportamento de Uso $(0,346)$. Isto quer dizer que a variação do construto Atitude é explicada pela variação dos preditores (Confiança, Expectativa de Desempenho, Hábito e Motivação Hedônica) em 53,5\% e as variações em Comportamento de Uso são explicadas pela variação de Hábito em 34,6\%. O $R^{2}$ represen- 
tando as variações do Risco Percebido sendo explicadas por Confiança, não foi significativo, $p$ valor acima de 0,05.

Pode-se afirmar que a análise estatística dos dados apoiou moderadamente o modelo de que os preditores (Confiança, Expectativa de Desempenho, Hábito e Motivação Hedônica) afetam a Atitude sendo que pela análise dos path coefficients, o Hábito apresentou a maior importância relativa $(0,311)$, seguida da Motivação Hedônica $(0,286)$, Confiança $(0,180)$ e Expectativa de Desempenho $(0,125)$. Já com respeito ao construto com portamento de uso, o construto Hábito se mostrou como um bom preditor, com um peso de 0,548, conforme Tabela 6 .

Considerando o ajuste do modelo, as medidas SRMR (standardized root mean square residual) e RMS theta (root mean square residual covariance) testam esse ajuste. Seguindo uma abordagem conservadora, um valor de SRMR ( RMS theta) menor do que $0,08(0,12)$ indica bom ajuste do modelo (Hair et al., 2016). Os valores alcançados para SRMR e RMS theta foram respectivamente 0,05 e 0,146, o que aponta um ajuste parcial do modelo aqui proposto. O Quadro 2 apresenta um resumo dos resultados das análises das hipóteses, com base nos resultados encontrados.

Sumariamente, pode-se dizer que, das hipóteses enunciadas, cinco foram apoiadas pelas analises estatísticas, a saber:

A significância da relação entre os constructos Expectativa de Desempenho (ED) e Atitude (AT) foi satisfatória, podendose afirmar que a Expectativa de Desempenho se constitui preditora da Atitude no presente estudo. Assim, os idosos percebem que o uso da internet propicia benefícios no desempenho de determinadas atividades, e quanto maior a expectativa deste desempenho mais intensa é a atitude favorável ao uso da internet, o mesmo foi encontrado por Nysveen e Pedersen (2016). Os autores Venkatesh, Thong e Xu, 2012 encontraram expectativa de desempenho (ED) sendo preditor de intenção comportamental, mas como no presente trabalho a atitude é predecessora de intenção, o construto ED apresentou esta relação positiva direta com a atitude.

O construto Hábito influenciou os construtos Atitude e o Comportamento de Uso. Tal influência tem relação com o observado por Esteves e Slongo (2012) ao compreenderem o crescente interesse por parte dos idosos em aprendizagem voltadas à novas tecnologias, utilizando-as a seu favor. Acrescenta-se a isso o exposto no PRC (2014), que constataram que a partir do momento em que o idoso adota uma tecnologia digital, ele a integra à sua vida cotidiana, tornando frequente o uso da mesma. Tanto a pesquisa dos autores supracitados quanto o relatório PRC, mostram relação direta com a definição de Hábito dada por Limayem, Hirt e Cheung (2007), que o define como a medida em que as pessoas tendem a comportamentos automáticos devido à aprendizagem. Assim, o Hábito afeta positivamente a Atitude (com peso de 0,311) e afeta diretamente o comportamento de uso (peso de 0,548). Esta última relação foi também ratificada por Lima Faria et al (2014) e Venkatesh, Thong e Xu (2012). Porém a relação da atitude como mediadora de Hábito e Comportamento de uso não foi significativa. 
Quadro 2- Análises das Hipóteses

\begin{tabular}{|c|c|c|c|}
\hline Hipótese & $\begin{array}{l}\text { Có- } \\
\text { digo }\end{array}$ & $\begin{array}{l}\text { Resul- } \\
\text { tado }\end{array}$ & Análise \\
\hline AT $\rightarrow$ IC & H11 & Rejeitada & A análise fatorial apontou a retirada do construto IC. \\
\hline $\mathrm{CF} \rightarrow \mathrm{CU}$ & $\mathrm{H} 6 \mathrm{~b}$ & Rejeitada & A análise fatorial apontou a retirada desse construto CF. \\
\hline CF $->$ AT & $\mathrm{H} 6 \mathrm{a}$ & Rejeitada & A análise fatorial apontou a retirada desse construto CF. \\
\hline CO $->$ AT & $\mathrm{H9}$ & Apoiada & $\begin{array}{l}\text { A significância da relação entre os constructos Confiança (CO) e Atitude (AT) } \\
\text { foi satisfatória, podendo-se afirmar que a Confiança se constitui um preditor } \\
\text { de Atitude para o estudo em questão. }\end{array}$ \\
\hline ED $->$ AT & $\mathrm{H} 2$ & Apoiada & $\begin{array}{l}\text { A significância da relação entre os constructos Expectativa de Desempenho } \\
\text { (ED) e Atitude (AT) foi satisfatória, podendo-se afirmar que a Expectativa de } \\
\text { Desempenho se constitui preditora da Atitude no presente estudo. }\end{array}$ \\
\hline EE -> AT & $\mathrm{H} 1$ & Rejeitada & $\begin{array}{l}\text { A significância da relação entre os constructos Expectativa de esforço (EE) e } \\
\text { Atitude (AT) não foi satisfatória, podendo-se afirmar que a Expectativa de } \\
\text { Esforço não se constitui como preditora da Atitude no presente estudo. }\end{array}$ \\
\hline $\mathrm{HT} \rightarrow \mathrm{CU}$ & $\mathrm{H} 5 \mathrm{~b}$ & Apoiada & $\begin{array}{l}\text { A significância da relação entre os constructos Hábito (HT) e Comportamento } \\
\text { de Uso (CU) foi satisfatória, podendo-se afirmar que o Hábito se constitui } \\
\text { como preditor do Comportamento de Uso. }\end{array}$ \\
\hline HT $\rightarrow$ AT & $\mathrm{H} 5 \mathrm{a}$ & Apoiada & $\begin{array}{l}\text { A significância da relação entre os Hábito (HT) e Atitude (AT) foi satisfatória, } \\
\text { podendo-se afirmar que o Hábito se constitui como preditor da Atitude. }\end{array}$ \\
\hline IC $->$ CU & $\mathrm{H7}$ & Rejeitada & A análise fatorial apontou a retirada do construto IC. \\
\hline IS -> AT & H3 & Rejeitada & $\begin{array}{l}\text { A significância da relação entre os constructos Influencia Social (IS) e Atitude } \\
\text { (AT) não foi satisfatória, podendo-se afirmar que a Influencia Social não se } \\
\text { constitui como preditor da Atitude no presente estudo. }\end{array}$ \\
\hline MH $->$ AT & $\mathrm{H} 4$ & Apoiada & $\begin{array}{l}\text { A significância da relação entre os constructos Motivações Hedônica (MH) e } \\
\text { Atitude (AT) foi satisfatória, podendo-se afirmar que a Atitude se constitui } \\
\text { como preditor da Atitude. }\end{array}$ \\
\hline RP $\rightarrow$ AT & H8 & Rejeitada & $\begin{array}{l}\text { A significância da relação entre os constructos Risco Percebido (RP) e Atitude } \\
\text { (AT) não foi satisfatória, podendo-se afirmar que o Risco Percebido não se } \\
\text { constitui como preditor da Atitude no presente estudo. }\end{array}$ \\
\hline CO $->$ RP & $\mathrm{H} 10$ & Rejeitada & $\begin{array}{l}\text { A significância da relação entre os constructos Confiança (CO) e Risco Perce- } \\
\text { bido (RP) não foi satisfatória, podendo-se afirmar que Confiança não afeta } \\
\text { negativamente o Risco Percebido no estudo em questão. }\end{array}$ \\
\hline AT $->$ CU & & Rejeitada & $\begin{array}{l}\text { Hipótese criada a partir da retirada do construto IC, ficando então uma relação } \\
\text { direta entre Atitude (AT) e comportamento de uso (CU). Porém foi rejeitada. }\end{array}$ \\
\hline
\end{tabular}

Fonte: Dados da pesquisa

Concernente ao construto Motivação Hedônica, a relação encontrada mostrou que tal construto influencia positivamente a Atitude. Isto significa que quanto mais intenso é o sentimento de diversão e/ou prazer proporcionado ao idoso pelo uso da internet mais a atitude ao uso da internet para fins turísticos fica favorável. No modelo UTAUT2 esta relação é confirmada, porém a Motivação Hedônica está direta e positivamente re- lacionada com a Intenção Comportamental, já no presente estudo o relacionamento é com a Atitude.

Outra hipótese que se mostrou significativa foi a referente à relação entre os construtos Confiança (CO) e Atitude (AT), podendo-se afirmar que a Confiança se constitui um preditor de Atitude para o estudo em questão. No trabalho de Slade et al. (2015), do qual o construto Confiança foi adotado, a 
relação Confiança e Intenção comportamental foi rejeitada. No presente estudo a Confiança mostrou-se afetando positivamente a Atitude. Assim, quanto mais confiança o idoso tem nas transações e nas empresas as quais ele se envolve na internet mais intensa será a atitude favorável ao uso da internet para fins turísticos.

Concernente às hipóteses rejeitadas, pode-se dizer que todas as hipóteses relacionadas aos construtos IC (Intenção comportamental) e CF (condições facilitadoras) não foram suportadas porque esses construtos foram excluídos em virtude da análise fatorial apontar a retirada dos mesmos.

Além destas, cinco hipóteses foram rejeitadas. A relação de influência exercida pelo construto Expectativa de Esforço no construto Atitude foi rejeitada, bem como houve a rejeição de: Influência Social como preditora da Atitude, Risco Percebido afetando negativamente a Atitude, Confiança influenciando negativamente o Risco Percebido e Atitude como preditora de Comportamento de Uso.

Em oposição aos achados de Nysveen e Pedersen (2016), a expectativa de esforço não se mostrou preditora da atitude de usar a internet para fins turísticos. Apesar da expectativa de esforço ser a percepção dos consumidores do grau de facilidade associada ao uso da internet, essa percepção de facilidade não mostra relação positiva com a atitude de utilização da tecnologia. Não se pode afirmar que o comportamento é distinto entre faixas etárias diferentes, o que se pode afirmar é que no trabalho tanto de Nysveen e Pedersen (2016) e Venkatesh, Thong \& Xu, 2012 o segmento estudado foi predominantemente público jovem. Sugere-se investigar mais a fundo a interferência da idade na definição dos determinantes da Atitude e Comportamento de uso.

Acredita-se que as razões de rejeição das hipóteses ligadas ao Risco Percebido (Risco Percebido e Atitude; Confiança e Risco Percebido) estejam ligadas à coleta de dados. Pode ter havido dificuldade de compreensão ou mesmo atenção ao responder às questões relativas a Risco Percebido, cuja escala era invertida, ou seja, uma concordância com a assertiva traduz uma resposta desfavorável.

A Influência Social no presente estudo também não foi apontada como um preditor da Atitude. Isso mostra que o segmento de idosos, pelos dados da pesquisa, não é tão influenciado pela pressão social ou rede de contatos para utilizar a internet quanto a faixa etária mais jovem (até 31 anos), a qual foi alvo do estudo de Venkatesh, Thong \& Xu, 2012, proponentes do UTAUT2.

A rejeição de hipóteses ainda se deu para a influência da Atitude no construto Comportamento de uso da Internet para fins turísticos. Essa relação direta foi testada no presente estudo de forma inédita, pois não foram encontrados trabalhos de outros autores. Porém não houve suporte empírico que comprovasse tal relação. Fica aqui mais uma sugestão para trabalhos futuros a verificação desta relação com amostras mais amplas e abrangendo várias faixas etárias.

\section{CONSIDERAÇÕES FINAIS}

As contribuições teóricas do presente trabalho se relacionam diretamente com o alcance de seus objetivos propostos inicial- 
mente à medida que, ao adotar o modelo UTAUT 2, juntamente com novos construtos (Atitude, Risco Percebido e Confiança) verificou-se aderência dos mesmos no âmbito turístico e tecnológico. A plausibilidade deste modelo modificado proposto foi comprovada pela aceitação de algumas hipóteses preconizadas, confirmando as relações dos construtos Hábito, Motivação Hedônica, Confiança e Expectativa de Desempenho como determinantes da Atitude de uso da Internet para fins turísticos e, acrescentando-se a isso, a relação do construto Hábito afetando positivamente o Comportamento de uso. Dentre os achados, destaca-se a confirmação de novos preditores para a Atitude, adequados ao contexto da tecnologia e turismo, corroborando com os estudos de Ajzen (1991) e Curras-Perez, Ruiz-Mafe e Sanz-Blas (2014) e Nysveen e Pedersen (2016) . Os determinantes de atitude no trabalho de Ajzen (1991) são as crenças (comportamentais, normativas e de controle). Enquanto que no trabalho de CurrasPerez, Ruiz-Mafe e Sanz-Blas (2014) os determinantes de atitude - no contexto de redes sociais - são sociabilidade, moda/status e entretenimento. No estudo de Nysveen e Pedersen (2016) os preditores de atitude são expectativa de desempenho, expectativa de esforço e ansiedade tecnológica.

O trabalho apresenta como contribuição gerencial, informações no tocante aos determinantes de atitude (Hábito, Motivação Hedônica, Confiança e Expectativa de Desempenho), uma vez que, em posse dessas informações, os gestores podem buscar compreender o comportamento de uso da internet para fins turísticos, possibilitando estratégias mais efetivas sobre viagens, compras de pacotes turístico, passagens e busca de informações.

Os achados também apresentam potencial de contribuição gerencial à medida que poderão subsidiar melhorias na comunicação enfatizando a Atitude favorável ao uso da internet. Além disso, as empresas do segmento de turismo podem adotar estratégias de estreitamento e aprofundamento do relacionamento da empresa com os clientes da terceira idade uma vez que a Confiança foi apontada como um dos determinantes de atitude em relação ao uso da internet e para o turismo. Além disso, frisar o aspecto divertido e de entretenimento propiciado pela internet ao idoso.

As implicações gerenciais corroboram com a visão de Pereira, Waismann e Dos Santos (2012) que percebem potencial nesse segmento, e defendem que, é necessário conhecer as aspirações e desejos desse público a fim de atendê-los melhor. Os autores acreditam que o número de pacotes e programas turísticos destinados a esse público não seja substancial, logo, é uma área para se explorar e investir.

O estudo apresentou como limitação, dificuldades relacionadas à utilização do método survey. A desvantagem encontrada no método é que os entrevistados podem não fornecer a informação correta ou não compreenderem as perguntas, relutar em responder questões delicadas ou pessoais (MaIhotra, 2006). No trabalho de campo, as principais queixas relativas à pesquisa, foram quanto ao tamanho do questionário, os entrevistados acharam muito extenso, cansativo e repetitivo, além disso, pode ter havido 
dificuldade de compreensão de algumas questões.

A generalização dos resultados deste estudo para o Brasil fica comprometida, uma vez que a amostra foi por conveniência. Sugere-se, dessa forma, a ampliação desta pesquisa contemplando uma amostra maior da terceira idade abrangendo todos os estados brasileiros.

Haja visto que os construtos Expectativa de Esforço, Influência Social, Risco Percebido, Intenção Comportamental e Condições Facilitadoras não se mostraram significativos no contexto do presente trabalho, sugere-se a realização de estudos futuros com outras amostras, ou seja, públicos e/ou contextos diferentes a fim de confirmar se tais relações existem.

\section{REFERÊNCIAS}

Ajzen, I. (1991) "The theory of planned behavior". Organizational Behavior and Human Decision Processes, 50(2), pp. 179-211.

Ashton, M. S. G., Cabral, S., Dos Santos, G. A. \& Kroetz, J. (2015). A relação do turismo e da qualidade de vida no processo de envelhecimento. Revista Hospitalidade, 2, pp. 547-566. BAIRD, C. H. \& PARASNIS, G. (2011). From social media to social customer relationship management. Strategy \& Leadership, 39(5), pp. 30-37.

Bhatiasevi, V. (2015). An extended UTAUT model to explain the adoption of mobile banking. Information Development.

Guerra, A. C., Gosling, M., \& Coelho, M. F. (2014). Redes Sociais: um jornal on-line como fonte de informação especializada em turismo. Revista Brasileira de Pesquisa em
Turismo, 8(3), pp. 403-418.

COMITÊ GESTOR DA INTERNET NO BRASIL (CGI), (2013). Pesquisa sobre o Uso das Tec nologias de Informação e comunicação no Brasil : TIC 2013. Disponível em: < http://cetic.br/publicacao/pesquisa-sobre-o-uso-das-tecnologiasde-informacao-e-comunicacao-tic-governo-eletronico-2013>. Acesso em: out/2016.

Cress, M. E., Buchner, D. M., Questad, K. A., Esselman, P. C. \& Schwartz, R. S. (1999). Exercise: effects on physical functional performance in independent older adults. The Journals of Gerontology Series A: Biological Sciences and Medical Sciences, 54(5), pp. M242-M248.

Curras-Perez, R., Ruiz-Mafe, C. \& Sanz-Blas, S. (2014). Determinants of user behaviour and recommendation in social networks: an integrative approach from the uses and gratifications perspective. Industrial Management \& Data Systems, 114(9), pp. 1477-1498.

D'Alencar, R. S. \& Veiga, R. de S. (2014). O Idoso no Turismo de Porto Seguro, BA. Memorialidades, 1(2), pp. 11-18.

De Carvalho, F. C. C. \& Da Silva, C. C. B. (2014). O Turismo e a Renda dos Idosos: a experiência brasileira com o Programa "Viaja Mais Melhor Idade". Anais Brasileiros de Estudos Turísticos$A B E T, 4(1)$, pp. 25-34.

Duarte, D.C., Santos, R. J. U \& Souza, C. F. (2015). Turismo e Hospitalidade: um estudo sobre a acessibilidade para o turista da terceira idade nos bares e restaurantes de Brasília. ANPTUR, Anais do Anptur.

Esteves, P. S. \& Slongo, L. A. (2012). A Internet e a Terceira Idade: Elaboração de um Modelo Teórico para a Compreensão deste Comportamento 
de Consumo. Anais do V Encontro de Marketing da ANPAD (EMA). Curitiba.

Farias, J. S., Da Luz Vitor, T., Lins, P. V. \& Pedroza Filho, L. E. A. (2015). Inclusão digital na terceira idade: um estudo sobre a propensão de idosos à adoção de tecnologias da informação e comunicação (TICs). Revista Gestão \& Tecnologia, Pedro Leopoldo, 15(3), pp. 164-188.

Fechine, B. R. A. \& Trompieri, N. (2015). O processo de envelhecimento: as principais alterações que acontecem com o idoso com o passar dos anos. InterSciencePlace, 1(20).

Fishbein e Ajzen (1975) Fishbein, M., and Ajzen, I. Belief, Attitude, Intention and Behavior: An Introduction to Theory and Research, AddisonWesley, Reading, MA, 1975.

Hair Jr, J. F; Black, W. C., Babin, B. J., Anderson, R. E. \& Tatham, R. L. (2010). Análise multivariada de dados. 6 ed. Porto Alegre: Bookman, 688p.

Hair Jr J. F., Hult, G. T. M., Ringle C. \& Sarstedt M. (2016). A Primer on Partial Least Squares Structural Equation Modeling (PLS-SEM). Second Edition.

Henseler, J., Ringle, C. M., \& Sarstedt, M. (2015). A new criterion for assessing discriminant validity in variance-based structural equation modeling. Journal of the Academy of Marketing Science, 43(1), 115-135.

IBGE - Instituto Brasileiro de Geografia e Estatística. Mudança Demográfica no Brasil no Início do Século XXI Subsídios para as projeções da população, (2015). Disponível em: http://biblioteca.ibge.gov.br/visualizacao/livros/liv93322.pdf . Acesso em: out/2016

IGDA. 2008-2009 "Casual Games White Paper".
Disponível em: archives.igda.org/casual/IGDA_Casual_Games. White_Paper_2008.pdf. (2008). Acesso em: nov/2016.

Kim, M. J. \& Preis, M. W. (2015). Why Seniors use Mobile Devices: Applying na Extended Model of Goal-Directed Behavior. Journal of Travel \& Tourism Marketing.

Kim, H., Woo, E., \& Uysal, M. (2015). Tourism experience and quality of life among elderly tourists. Tourism Management, 46, 465-476.

Kuo, H. M., Chen, C. \& Wu; H., C.H. (2012). A study of a B2C supporting interface design system for the elderly. Human Factors and Ergonomics in Manufacturing \& Service Industries, 22(6), pp. 528-540.

Lima Faria, H. L.; Giuliani, A. C., Pizzinatto, N. K., \& Pizzinatto, A. K. (2014). A Aplicabilidade do Modelo Estendido ao Consumo da Teoria Unificada da Aceitação e Uso de Tecnologia (UTAUT2) no Brasil: Uma Avaliação do Modelo a partir de Usuários de Internet em Smartphones. Rev. Adm. UFSM, Santa Maria, 7(2), pp. 332-348.

Limayem, M., Hirt, S. G. \& Cheung, C. M. K. (2007). How Habit Limits the Predictive Power of Intentions: The Case of IS Continuance, MIS Quarterly (31)4, pp. 705-737.

Liz, E., Ruschmann, D. V. De M. \& Verdinelli M. A. (2011). Turismo e Lazer para a Terceira Idade: Perspectivas e Desafios. VIII Seminário da Associação Nacional de Pesquisa e Pós-Graduação em Turismo. Anais... Univali, SC.

Lu, Y., Yang, S., Chau, P. \& Cao, Y. (2011). Dynamics between the trust transfer process and intention to use mobile payment services: A cross-environment perspective. Information \& Management, 48, pp.393-403. 
Luz, J. R. C. P. R. (2016). A intenção de adoção do $Q R$ code em Portugal pelos utilizadores finais.

Doctoral dissertation, Instituto Superior de Economia e Gestão.

Malhotra, N. (2006). Pesquisa de marketing: uma orientação aplicada. 4. ed. Porto Alegre: Bookman.

Malhotra, N. K., Birks, D. \& Wills, P. (2012). Marketing research: applied approach. 4. ed. New York: Pearson.

Mello, C., De Liz, E. \& Verdinelli, M. A. ( 2015). Acessibilidade e Segurança da pessoa idosa no espaço público. Segurança: Um Desafio Para Os Setores De Lazer, Viagens E Turismo. Tomar, Portugal.

Moura, A. C, Godinho, L. A., Gosling, M. E Martins, J. F (2014). Marketing de relacionamento via redes sociais: uma análise de sua aplicação. Revista Eletrônica de Administração (Online), 13(1).

Moura, E. F. S., Souza, E. M. M. De; Medeiros, J. R.De \& Maracajá, K. F.B. (2012). Turismo na terceira idade: uma análise do forró dos idosos na cidade de Currais Novos-RN. Revista Querubim. 2(16).

Noguera, J. M., Barranco, M. J., Segura, R. J., \& Martínez, L. (2012). A mobile 3D-GIS hybrid recommender system for tourism. Information Sciences, 215, 37-52

Nysveen, H., \& Pedersen, P. E. (2016). Consumer adoption of RFID-enabled services. Applying an extended UTAUT model. Information Systems Frontiers, 18(2), 293-314.

Oliveira, B. M. K., Ramos, A. S. M., de Andrade, A. P. V., de Souza Neto, R. A., \& Dias, G. F.
(2015). Fatores influenciadores na adoção de capacitação a distância. Revista Pretexto, 16(4), 100-118.

Oliveira, L. F. D. (2015). A utilização de jogos online no processo seletivo: caso de uma empresa de consultoria em Brasília. Repositório do centro universitário de Brasilia.

Pereira, R. F., Waismann, V. \& Dos Santos, R. B. S. (2012). Turismo para melhor idade: uma perspectiva de qualidade de vida. Norte Científico, $4(1)$.

PEW RESEARCH CENTER - PRC. (2014).Older adults and technology use. Disponível em http://www. pewinternet.org/2014/04/03/older-adults-and-technol ogy-use. Acesso em: out/16.

Qualman, E. (2011). Como as mídias sociais es tão transformando a forma como vivemos e fazemos negócios. São Paulo: Saraiva.

Ramalho, W. (2006) .Modelos de atitude em mercados de novos entrantes : análise com medicamentos genéricos, contribuições teóricas e validação nomológica. Tese (Doutorado) - Universidade Federal de Minas Gerais, Centro de Pós-Graduação e Pesquisas em Administração.

Rho, M. J., Kim, H. S., Chung, K., \& Choi, I. Y. (2015). Factors influencing the acceptance of telemedicine for diabetes management. Cluster Computing, 18(1), 321-331.

Rodriguez-Sanchez, M. C., Martinez-Romo, J., Borromeo, S., \& Hernandez-Tamames, J. A. (2013). GAT: Platform for automatic contextaware mobile services for m-tourism. Expert Systems with Applications, 40 (10). 
Santos, L. G. N. O, Ishitani, L. \& Nobre, C. N. (2013). Uso de jogos casuais em celulares por idosos: um estudo de usabilidade. Revista de Informática Aplicada , 9(1).

Santos, S. S. C. (2010). Concepções teórico-filosóficas sobre envelhecimento, velhice, idoso e enfermagem gerontogeriátrica. FURG, Rio Grande.

Sharma, N. \& Patterson, P.G. (2000). Switching costs, alternative attractiveness and experience as moderators of relationship commitment in professional, consumer services. International journal of service industry management, 11(5), pp. 470-490.

Schein, M., Perin, M. G., Sampaio, C. H., \& De Ugalde, M. M. (2009). O comportamento da compra de serviços de turismo na terceira idade. Turismo-Visão e Ação, 11(3), pp. 341-357.

Slade, E. L., Dwivedi, Y. K., Piercy, N. C. \& Williams, M. D. (2015). Modeling Consumers Adoption Intentions of Remote Mobile Payments in the United Kingdom: Extending UTAUT with Innovativeness, Risk, and Trust. Psychology \& Marketing, 32(8), pp. 860-873.

Sousa, B. M. (2016). A dinâmica diferenciadora e o processo de criação na gestão de destinos turísticos. Revista Brasileira de Pesquisa em Turismo, 10(1), 3-17.

Souza Meirelles, F., \& Longo, L. (2015). Adoção de plataforma estratégica de tecnologia de informação e comunicação: análise baseada no modelo UTAUT. Revista da FAE, 17 (1), 110-125.

Thakur, R. \& Srivastava, M. (2014). Adoption readiness, personal innovativeness, perceived risk and usage intention across customer groups for mobile payment services in India. Internet Research, 24, 369-392.
Toni, I. M. (2014). Universidade da Terceira Idade espaço de novos saberes para novos fazeres. Memorialidades, 8(15), pp. 63-84.

Trigo, L. G. G. (2005). Análises Regionais e Globais do Turismo Brasileiro. São Paulo: Roca.

Uysal, M., Sirgy, M. J., Woo, E., \& Kim, H. L. (2016). Quality of life (QOL) and well-being research in tourism. Tourism Management, 53, 244-261.

Venkatesh, V., Morris, M. G., Davis, G. B. \& Davis, F. D. (2003). User Acceptance of information Technology: toward a unified view. MIS Quarterly. 27(3), pp. 425-478.

Venkatesh, V, Thong, J. L. \& Xu, X. (2012). Consumer acceptance and use of information Technology: extending the unified theory of acceptance and use of technology. MIS Quarterly . 36(1), pp. 157-178.

Vera, L. A. R. (2014). Fatores motivadores de compras coletivas na internet: um estudo com base no modelo de aceitação e uso de tecnologia 2. Dissertação (Mestrado) - Universidade Federal da Bahia, Salvador.

Vilela, A. B. A., Carvalho, P. Dos A. Li. De \& Araújo, R.T. De. (2006). Envelhecimento bem-sucedido: Representação de Idosos. Revista Saúde.com , pp. 101-114.

Williams, M., Rana, N., Dwivedi, Y. \& Lal, B.( 2011). Is UTAUT really used or just cited for the sake of it? A systematic review of citations of UTAUT's originating articles. Proceedings of the European Conference on Information Systems, June 9-11, 2011, Helsinki, paper 231.

Zhou, T. (2013). An empirical examination of continuance intention of mobile payment services. Decision Support Systems, 54, 1085-1091. 


\section{Dados dos Autores}

\section{Andréia Cássia de Moura}

Doutoranda em Administração pelo Programa de PósGraduação em Administração da Universidade Federal de Minas Gerais - UFMG, Mestre em Administração pela UFMG, Especialista em Gestão Estratégica pela UFMG e Bacharel em Administração pela UFMG.Email: andreia.moura@estacio.br

\section{Marlusa de Sevilha Gosling}

Doutora em Administração pelo Programa de Pós-Graduação em Administração da Universidade Federal de Minas Gerais - UFMG e posdoc em Gestão do Turismo na Universidade de Algarve, Mestre em Administração pela UFMG. Bacharel em Ciência da Computação pela UFMG. Professora de Marketing da UFMG, Coordenadora do NEECIM-TUR (Núcleo de Estudos e Estratégias em Comunicação Integrada de Marketing e Turismo). E-mail: mg.ufmg@gmail.com

\section{Juliana Maria Magalhães Christino}

Doutora em Administração pelo Programa de PósGraduação em Administração da Universidade Federal de Minas Gerais - UFMG. Mestre em Administração pela FEAD. Especialista em Marketing pela FGV. Bacharel em Administração pela Pontifícia Universidade Católica de Minas Gerais. Professora adjunta do curso de Administração da UFMG. E-mail: julianam.prof@gmail.com

\section{Sâmara Borges Macedo}

Doutoranda em Administração pelo Programa de PósGraduação em Administração da Universidade Federal de Minas Gerais - UFMG. Mestre em Administração pela Universidade Federal de Lavras - UFLA. Bacharel em Administração pela Universidade Federal de São João Del Rei - UFSJ. E-mail: samaraborgesmacedo@outlook.com 